\title{
The Sweet Side of Plant-Specialized Metabolism
}

\author{
Thomas Louveau and Anne Osbourn \\ Department of Metabolic Biology, John Innes Centre, Norwich Research Park, Norwich NR4 7UH, \\ United Kingdom \\ Correspondence: anne.osbourn@jic.ac.uk
}

Glycosylation plays a major role in the structural diversification of plant natural products. It influences the properties of molecules by modifying the reactivity and solubility of the corresponding aglycones, so influencing cellular localization and bioactivity. Glycosylation of plant natural products is usually carried out by uridine diphosphate (UDP)-dependent glycosyltransferases (UGTs) belonging to the carbohydrate-active enzyme glycosyltransferase 1 (GT1) family. These enzymes transfer sugars from UDP-activated sugar moieties to small hydrophobic acceptor molecules. Plant GT1s generally show high specificity for their sugar donors and recognize a single UDP sugar as their substrate. In contrast, they are generally promiscuous with regard to acceptors, making them attractive biotechnological tools for small molecule glycodiversification. Although microbial hosts have traditionally been used for heterologous engineering of plant-derived glycosides, transient plant expression technology offers a potentially disruptive platform for rapid characterization of new plant glycosyltransferases and biosynthesis of complex glycosides.

$\mathrm{C}$ ollectively, plants synthesize a diverse array of chemicals, most likely as a means of survival in diverse ecological niches. These molecules have been variously associated with abiotic stress resistance (Trossat et al. 1998; Nuccio et al. 1999), defense against herbivores and pathogens (Osbourn 1996; Vetter 2000; Howe and Jander 2008), establishment of symbiotic interactions (Oldroyd 2013), allelopathy (Weston and Mathesius 2013), and attraction of pollinators (Ogata et al. 2005; Theis and Raguso 2005; Yu and Utsumi 2009). Plant-specialized metabolites are derived from a repertoire of different types of scaffolds. These scaffolds commonly undergo further modification (e.g., oxidation, glycosylation, methylation, and acylation) to generate a wealth of chemical diversity, with around one million specialized metabolites being reported from plants so far (Afendi et al. 2012). Among these modifications, glycosylation has a profound impact on the physicochemical and bioactive properties of phytochemicals, affecting solubility, cellular localization, and bioactivity.

Here we review recent developments in understanding the enzymes involved in plant natural product glycosylation. We also consider the various heterologous expression hosts used for metabolic engineering of plant glycosides. Finally, we discuss the potential for harnessing enzymes from plants for glycodiversification of small molecules for medicinal, agronomic, and industrial applications.

Editor: Pamela C. Ronald

Additional Perspectives on Engineering Plants for Agriculture available at www.cshperspectives.org

Copyright (C 2019 Cold Spring Harbor Laboratory Press; all rights reserved; doi: 10.1101/cshperspect.a034744

Cite this article as Cold Spring Harb Perspect Biol 2019;11:a034744 


\section{GLYCOSYLATION OF PLANT-SPECIALIZED METABOLITES}

The Impact of Glycosylation on Bioactivity

Many plant-specialized metabolites accumulate as glycosides. Glycosylation is often a means of storage of bioactive molecules (e.g., endogenous phytoanticipins or xenobiotics). While some plant glycosides are biologically active in their glycosylated form, in other cases partial or complete hydrolysis of sugars may activate or enhance bioactivity (Fig. 1). In scenarios where glycosylation is required for bioactivity, complex glycosylation patterns are often observed. For example, triterpenoid saponins and steroidal glycoalkaloids often contain oligosaccharide chains consisting of different types of sugar units (Vincken et al. 2007). Such compounds protect plants against attack by pathogenic microbes, herbivores, and competing plant species
(Augustin et al. 2011; Sawai and Saito 2011). Two examples, avenacin A-1 from oat and $\alpha$-tomatine from tomato, are shown in Figure 1A. Glycosylation is critical for the ability of triterpenoid saponins and steroidal glycoalkaloids to integrate into and permeabilize plasma membranes, and also for bioactivity (Bowyer et al. 1995). Glycosylation is also important for flavonoid pigment stability, enabling intra- and intermolecular association of anthocyanins with other flavonoids, metal ions (metalloanthocyanins), or aromatic organic acids under conducive $\mathrm{pH}$ conditions. The central role of flavonoid glycosidic moieties in formation of such hydrophobic stacking structures has recently been demonstrated by the engineering of blue chrysanthemums (Noda et al. 2017). Ternatin D3, one of the anthocyanins responsible for the blue coloration of Clitoria ternatea, is also shown in Figure 1A.
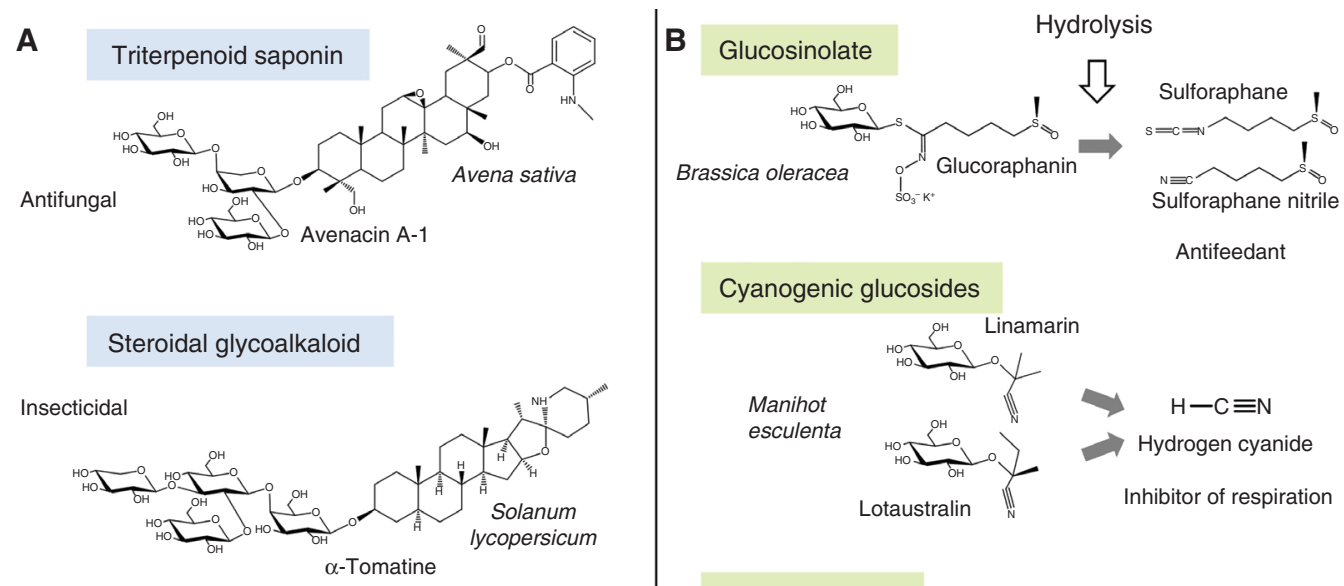

Cyanogenic glucosides
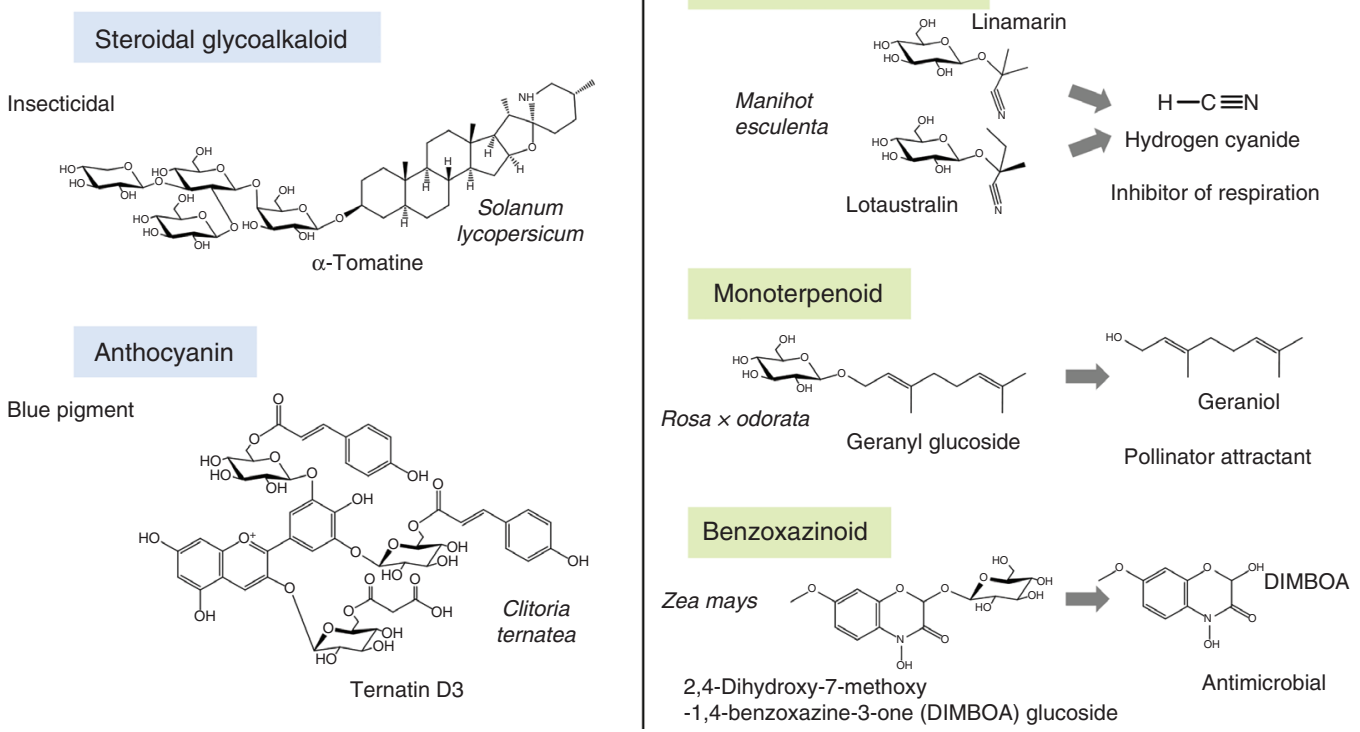

Figure 1. Examples of glycosylated plant-specialized metabolites. Compounds that are active in their fully glycosylated forms $(A)$ or upon hydrolysis $(B)$ are shown. 
Glucosinolates and cyanogenic glucosides (Fig. 1B) are examples of situations where glycosylated plant natural products are activated by removal of sugars to give deterrent or toxic breakdown products that provide protection against pest and pathogen attack. The enzymes that catalyze deglucosylation (thiospecific glucohydrolases myrosinases or specific $\beta$-glycosidases, respectively) are normally stored away from their substrates in separate subcellular compartments or cell types but are released on tissue damage (Hopkins et al. 2009; Gleadow and Møller 2014). Other examples of activation of plant natural products by hydrolysis of sugars include glycoside-bound volatiles (e.g., monoterpenes, sesquiterpenes, phenolics) with various roles in pollinator attraction, biotic/ abiotic stress tolerance, and communication between plants (e.g., geranyl glucoside) and benzoxazinoid defense compounds (e.g., 2,4-dihydroxy-7-methoxy-1,4-benzoxazinone-3-one (DIMBOA) glucoside) (Fig. 1B; de Bruijn et al. 2018; Song et al. 2018). Those compounds that are activated by hydrolysis, in general, have relatively simple glycosidic moieties and are usually mono- or diglycosides, typically containing D-glucose.

Glycosyl Transferase Family 1 (GT1): An Engine for Glycodiversification

Enzymes that build or break down the considerable diversity of glycosylated structures found in living organisms (e.g., proteins, lipids, polysaccharides) are collectively referred to as carbohydrate-active enzymes (CAZymes) (Cantarel et al. 2009). CAZymes include the glycosyltransferases (GTs), a large enzyme superfamily that has been classified into 106 different enzyme families (www.cazy.org/ glycosyltransferases.html). The enzymes that are primarily responsible for glycosylation of plant natural products belong to glycosyltransferase family 1 (GT1). Members of the GT1 enzyme family in plants use uridine diphosphate (UDP)-activated sugar donors to transfer sugar units onto small molecules and are therefore also referred to as UDP-dependent glycosyltransferases (UGTs).
GT1 enzymes make major contributions to the glycodiversification of plant-specialized metabolites (Vogt and Jones 2000; Bowles et al. 2006). They are involved in the production of important defense compounds such as terpenoid glycosides, glucosinolates, cyanogenic glycosides, and flavonoid glycosides (Sønderby et al. 2010; Sawai and Saito 2011; Gleadow and Møller 2014). The stability of pigments (e.g., anthocyanins), the taste of fruit (e.g., flavonoids, diterpenoids), and the retention of aromas in flowers or fruits (e.g., monoterpenes, phenyl alcohols) are also modulated via GT1-mediated glycosylation (Noda 2018; Song et al. 2018). GT1 enzymes are also involved in regulation of plant growth and development via modulation of phytohormone homeostasis (Piotrowska and Bajguz 2011). They further enable xenobiotic detoxification through glucoconjugation, a step that precedes transfer and subsequent storage of the modified xenobiotic in the vacuole (Brazier-Hicks et al. 2018).

\section{GT1 PHYLOGENY}

The family 1 GTs are one of the largest groups of natural product-decorating enzymes in plants. The expansion of this family in higher plants likely reflects chemical diversification during adaptation to life on land (Yonekura-Sakakibara and Hanada 2011; Caputi et al. 2012). Mining of the complete genome sequence of Arabidopsis thaliana has identified 107 predicted GT1 genes. These GT1 enzymes have been classified into 14 monophyletic groups (groups A to N) (Ross et al. 2001). Three new phylogenetic groups ( $\mathrm{O}, \mathrm{P}$, and $\mathrm{Q})$, which are not found in A. thaliana but are present in other plant species, have also subsequently been reported (Fig. 2; Caputi et al. 2012; Li et al. 2014).

Most plant GT1 enzymes use UDP glucose as their sugar donor. However, the ability to use alternative sugar donors appears to have evolved multiple times, and closely related enzymes may use different sugar donors. This is illustrated by three closely related $A$. thaliana group F flavonoid GTs, UGT78D1, UGT78D2, and UGT78D3 (indicated by asterisks in Fig. 2), each of which use a different UDP sugar donor 


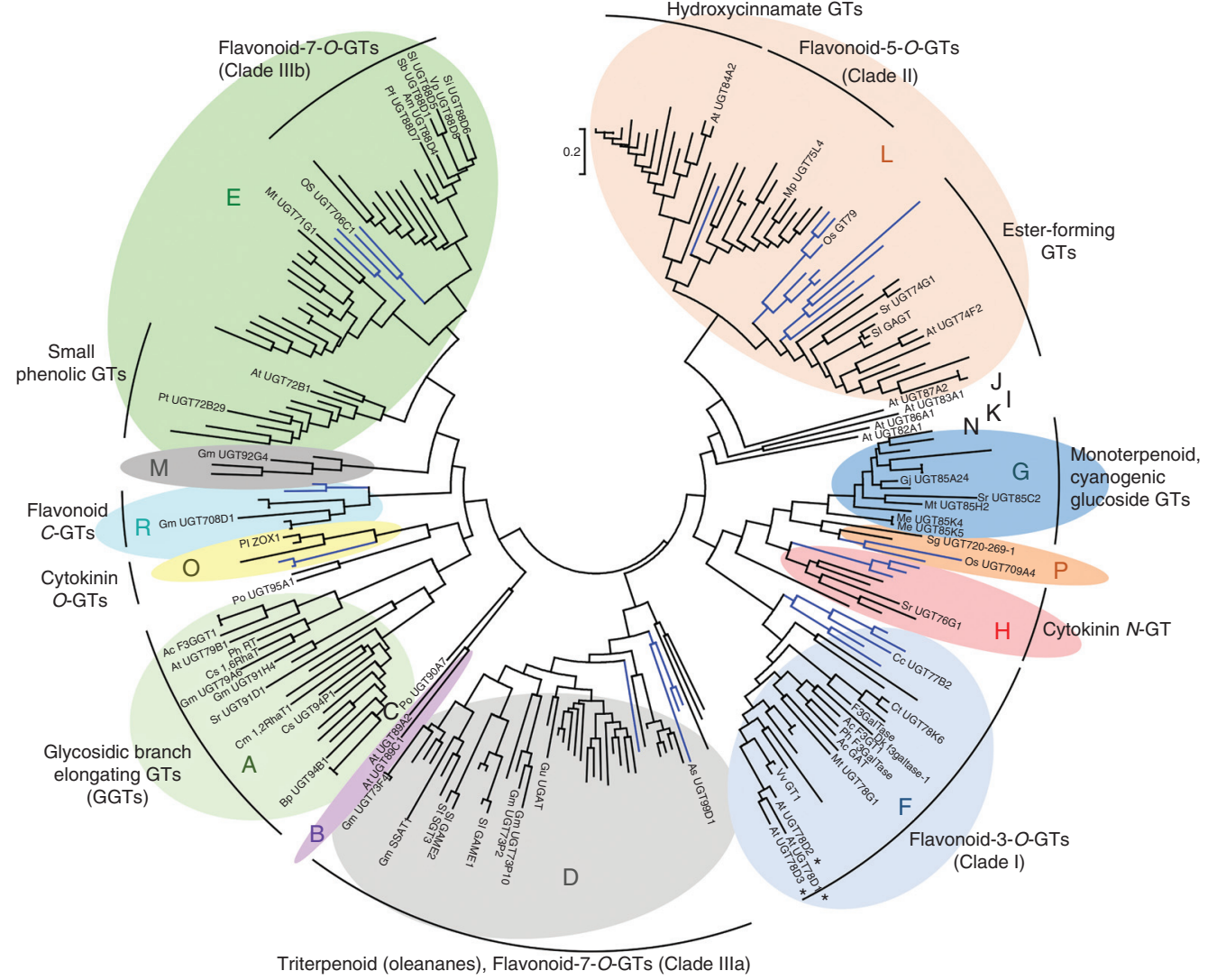

Figure 2. Phylogenetic tree of characterized plant glycosyltransferases 1 (GT1s). Reconstruction of GT1 phylogeny from a collection of 246 biochemically characterized GT1 protein sequences. The groups are delineated as defined by Ross et al. (2001) and Caputi et al. (2012). Discrete clusters of enzymes with similar activities are indicated. Monocot-specific branches are shown in blue. The tree was constructed with Mega 6.06 (Tamura et al. 2013) using the maximum likelihood method from a protein alignment obtained with MUSCLE 3.8 (Edgar 2004). *, Closely related Arabidopsis thaliana family F GT1s with different sugar specificities (see main text). The scale bar indicates 0.2 substitutions per site at the amino acid level.

(Jones et al. 2003; Tohge et al. 2005; YonekuraSakakibara et al. 2008). The discovery that a small number of key amino acid residues are critical for sugar donor specificity may explain the rapid evolution of sugar donor specificity observed throughout the phylogeny.

Although some light has been shed on determinants of sugar donor specificity, the determinants of acceptor recognition remain obscure and the link between phylogeny and acceptor utilization is not always straightforward. However, careful examination of the phylogenetic reconstruction of functionally characterized GT1s does reveal discrete clustering of GT1s with structurally related acceptors or functions (Fig. 2). Early phylogenetic studies of comprehensive collections of plant GT1 enzymes have focused mainly on flavonoid GTs. The tree topology of flavonoid GT1s broadly recapitulates their regiospecificity (Vogt and Jones 2000; Lim et al. 2004), suggesting that regiospecificity emerged prior to speciation. Different types of flavonoid GTs are located in four distinct (sub)clades that correlate with their respective regiospecificities (Fig. 2; Vogt and Jones 2000; Noguchi et al. 2009). Another group (group A) contains GT1s that extend flavonoid sugar chains, and also enzymes that add sugars 
to the sugar chains of a variety of other types of scaffolds, collectively referred to as glycosidic branch elongating GTs (GGTs) (Fig. 2). Additional discrete clusters of GT1s that recognize structurally similar acceptors have also been recently identified (Augustin et al. 2011; Yonekura-Sakakibara and Hanada 2011). An important monophyletic group composed exclusively of $C$-GTs has emerged in recent work (Nagatomo et al. 2014), labeled as group R in Figure 2. However, there are many exceptions to the premise that GT1 function can be predicted based on phylogeny alone. For example, numerous examples of enzymes that add sugars to the sugar chains of plant natural products have been found outside of group A (Mohamed et al. 2011; Sayama et al. 2012; Itkin et al. 2013). Similarly, whereas a number of triterpenoid GT1s are present in group $\mathrm{D}$, there are numerous examples of triterpenoid GT1s that belong to other GT1 families (Achnine et al. 2005; Jung et al. 2014; Wei et al. 2015).

A growing number of monocot GT1s have now been characterized. Some of these fall into monocot-specific GT1 subfamilies within the larger monophyletic groups (D, E, and L) (Fig. 2; Caputi et al. 2012). Most of these GT1s seem to have similar acceptor specificity to their eudicot relatives within the same monophyletic group, although further work is needed to establish whether these monocot-specific subfamilies are functionally equivalent to their eudicot counterparts.

\section{GT1s-PROMISCUOUS BIOCATALYSTS FOR SCAFFOLD GLYCOSYLATION}

UGTs catalyze the transfer of a sugar from a UDP sugar donor to an acceptor (usually a lipophilic molecule). GT1s generally show high specificity for their sugar donors and a single activated sugar is efficiently recognized as the substrate (Osmani et al. 2009). Plant GT1 enzymes accommodate their sugar donors primarily via a highly conserved motif (Fig. 3A) called the plant secondary product glycosyltransferase (PSPG) motif (Hughes and Hughes 1994; Ross et al. 2001). In contrast to the observed specificity for particular sugar donors, in vitro studies using recombinant enzymes from $A$. thaliana have highlighted the promiscuity of many GT1s with regard to acceptor recognition (Vogt and Jones 2000; Lim et al. 2002; Caputi et al. 2008). For example, UGT85K4 and UGT85K5 from cassava (Manihot esculenta) (group G) are involved in cyanogenic glucoside biosynthesis. The ability of these enzymes to glycosylate precursors of the cyanogenic glycosides linamarin and lotaustralin in vitro is consistent with their role in planta. However, these enzymes also recognize a wide range of other acceptors in in vitro assays, including flavonoids, simple alcohols, and various hydroxynitriles (Kannangara et al. 2011). In contrast, other GT1s show high specificity toward one or a few structurally related compounds. For example, UGT85A24 from Gardenia jasminoides, which is part of an iridoid biosynthetic pathway, shows high specificity toward the iridoid 7-deoxyloganetin but does not exhibit activity toward the immediate precursor 7-deoxyloganetic acid (Nagatoshi et al. 2011). Most GT1s act on hydroxyl or carboxyl groups, but $N_{-}, S_{-}$, or $C$-glycosylation can also occur (Jones and Vogt 2001; Grubb et al. 2004; Hou et al. 2004; BrazierHicks et al. 2007b, 2009; Wang et al. 2011).

\section{STRUCTURES OF PLANT GT1 ENZYMES}

To date, a total of nine crystal structures of plant GT1s have been solved (Table 1; Shao et al. 2005; Offen et al. 2006; Brazier-Hicks et al. 2007a; Li et al. 2007; Modolo et al. 2009; Hiromoto et al. 2015; Wetterhorn et al. 2016; George Thompson et al. 2017; Hsu et al. 2018). Although those enzymes have relatively low amino acid sequence identity (typically 25\%-45\%), they share very similar 3D structures (Osmani et al. 2009; Wang 2009). This common structure is called the GT-B fold and is formed of two Rossmannlike domains, composed of central $\beta$-strands surrounded by several $\alpha$-helices (Fig. 3B). The catalytic site is localized in a cleft between the two domains.

In plant GT1s, two highly conserved residues play a crucial part in the $\mathrm{S}_{\mathrm{N}} 2$-like mechanism in which the stereochemistry of the $\mathrm{C} 1$ anomeric carbon is inverted during the reaction, 


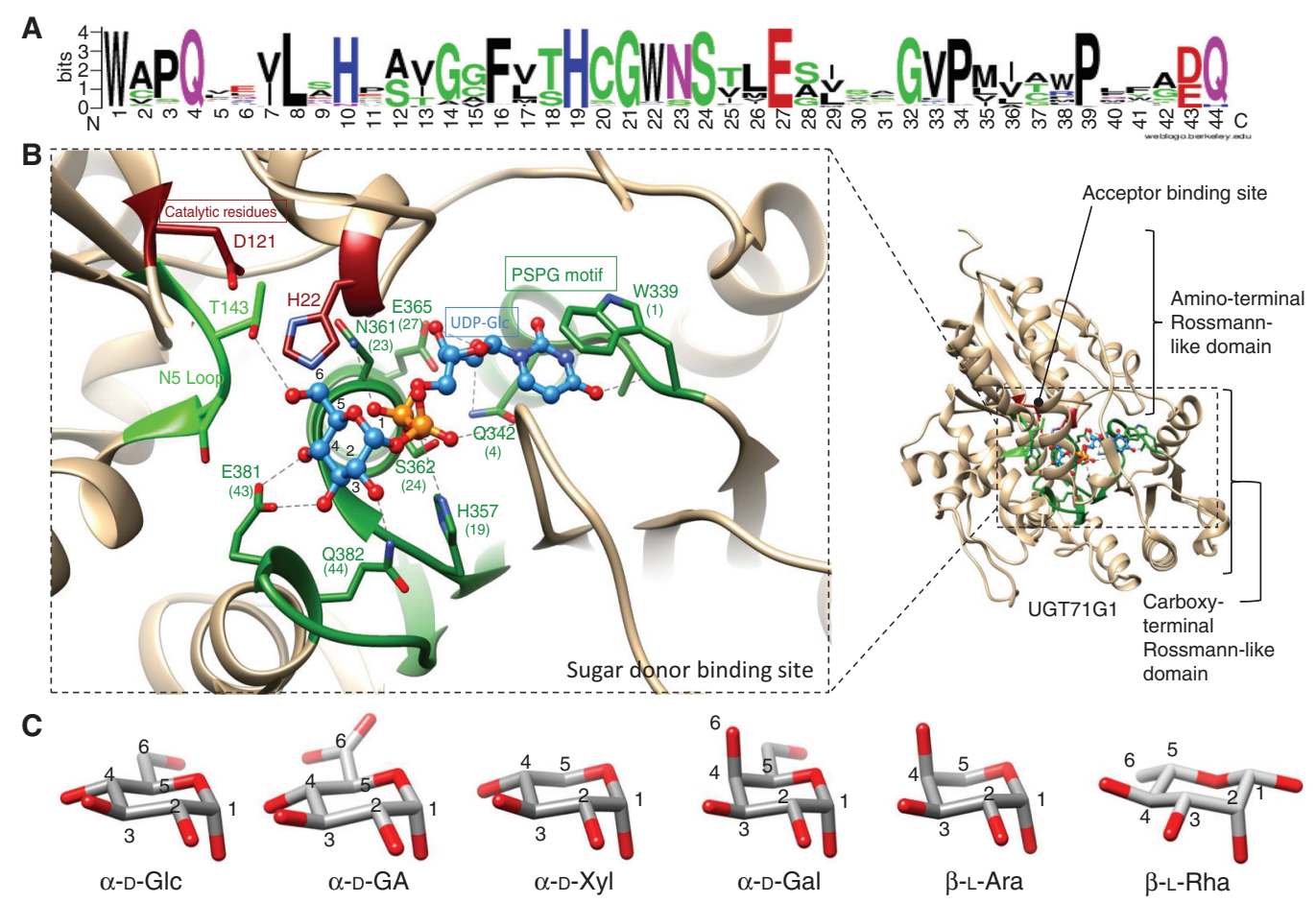

Figure 3. Determinants of sugar specificity of plant glycosyltransferases 1 (GT1s). (A) Consensus plant secondary product glycosyltransferase (PSPG) motif generated by weblogo (weblogo.berkeley.edu) from an alignment of characterized GT1s. (B) The sugar donor-binding site for the crystal structure of the GT1 enzyme UGT71G (a flavonoid/triterpenoid O-glucosyltransferase Medicago truncatula) in complex with uridine diphosphate glucose (UDP-Glc) (PDB code 2ACW). The PSPG motif is shown in dark green, the N5 loop in light green, and catalytic residues in dark red. UDP-Glc is shown as a ball and stick model and colored in blue. Proposed hydrogen bonds are shown as dashed lines. $(C)$ Compared structures of most common sugar donors of plant GT1s.

making them inverting GTs (Fig. 4A; Wang 2009). A histidine positioned around the 20th residue (Fig. 3A) acts as a general base to deprotonate the acceptor. Nucleophilic attack of the $\mathrm{C} 1$ carbon of the UDP-sugar is achieved by the deprotonated acceptor (Fig. 4A; Lairson et al. 2008; Wang 2009). A conserved aspartate residue in proximity to the histidine has been proposed to help to balance the charge from the histidine to form an acceptor-His-Asp catalytic triad (Fig. 4A). However, the existence of rare examples where those residues are not conserved suggests that alternative catalytic mechanisms might take place (Noguchi et al. 2007; Wang et al. 2011, 2013; Wilson et al. 2017). The crystal structure of the ester-forming salicylic acid glucosyltransferase UGT74F2 from
A. thaliana suggests that other residues could be used to help deprotonate the acceptor for nucleophilic attack by a carboxylate oxygen (George Thompson et al. 2017). Similar mechanisms may also exist in ester-forming UGT families that lack the catalytic aspartate (Wilson et al. 2017). The recent crystallization of the deoxynivalenol-glucosyltransferase Os79 from rice, coupled with site-directed mutagenesis, suggests that Thr291 plays a critical role in either positioning the $\beta$-phosphate of UDP or protonating it (Wetterhorn et al. 2016). This residue is extremely well conserved in all UGTs as either a serine or threonine (Ser/Thr in Fig. 4A), with a few exceptions, including the Lamiales flavonoid 7-O-glucuronosyltransferase UGT88Ds (replaced by arginine), the $A$. thaliana arabino- 
Plant Natural Product Glycosylation

Table 1. Plant GT1 enzymes for which crystal structures have been determined

\begin{tabular}{|c|c|c|c|c|}
\hline $\begin{array}{l}\text { Gene } \\
\text { name }\end{array}$ & Species & $\begin{array}{l}\text { PDB } \\
\text { entry }\end{array}$ & Activity & References \\
\hline UGT71G1 & Medicago truncatula & $2 \mathrm{ACW}$ & $\begin{array}{l}\text { Flavonoid/triterpenoid } O \text { - } \\
\text { glucosyltransferase }\end{array}$ & Shao et al. 2005 \\
\hline VvGT1 & Vitis vinifera & $2 \mathrm{C} 1 \mathrm{Z}$ & Flavonoid 3-O-glucosyltransferase & Offen et al. 2006 \\
\hline UGT72B1 & Arabidopsis thaliana & $2 \mathrm{VCH}$ & $\begin{array}{l}\text { Chlorinated phenols } \mathrm{N} / \mathrm{O}- \\
\text { glucosyltransferase }\end{array}$ & Brazier-Hicks et al. 2007a \\
\hline UGT85H2 & M. truncatula & 2PQ6 & Flavonoid 3-O-glucosyltransferase & Li et al. 2007 \\
\hline UGT78G1 & M. truncatula & $3 \mathrm{HBF}$ & Flavonoid 3-O-glucosyltransferase & Modolo et al. 2009 \\
\hline UGT78K6 & Clitoria ternatea & 4REM & Flavonoid 3-O-glucosyltransferase & Hiromoto et al. 2015 \\
\hline Os79 & Oryza sativa & 5TME & Deoxynivalenol $O$-glucosyltransferase & Wetterhorn et al. 2016 \\
\hline UGT74F2 & A. thaliana & $5 \mathrm{U} 6 \mathrm{M}$ & Salicylic acid $O$-glucosyltransferase & George Thompson et al. 2017 \\
\hline UGT72B29 & Persicaria tinctoria & $5 N L M$ & Indoxyl O-glucosyltransferase & Hsu et al. 2018 \\
\hline
\end{tabular}

syltransferase UGT78D3 (replaced by arginine), the majority of the $C$-glucosyltransferases from group $\mathrm{Q}$ (replaced by asparagine), and the cassava $\alpha$-hydroxynitrile glucosyltransferases UGT85K4 and UGT85K5 (replaced by cysteine). These striking amino acid substitutions in GT1s with noncanonical substrates could suggest a pivotal role for this residue position in determining the substrate specificity and catalytic properties of GT1s.

\section{ACCEPTOR RECOGNITION}

The determinants of acceptor recognition in GT1s are poorly understood (Osmani et al. 2009; Wang 2009). GT1 acceptor promiscuity is reflected by the nature of the acceptor-binding site, which consists primarily of a large apolar pocket within the amino-terminal domain (Fig. 3B). Residues within the acceptor-binding pocket are located in regions that are poorly conserved in plant GT1s (Osmani et al. 2009). Little is known about the mechanisms underlying the correct orientation of the acceptor molecule and therefore the regiospecificity of glycosylation catalyzed by GT1s. Hydrophobic stacking of apolar acceptors by aromatic residues, plus the steric constraints relative to the shape and volume of the pocket, seem to be the primary determinants of acceptor recognition. The regiospecificity of particular GT1 isoforms appears to be defined by local subtle variations in the polarity and elec- tronic surroundings of the binding pocket, allowing interactions of GT1s with their ligands (He et al. 2006; Li et al. 2007; Modolo et al. 2009). This is particularly exemplified by the crystal complexes of UGT78K6, an anthocyanidin 3-O-glucosyltransferase from C. ternatea, where polar residues surrounding the binding site allow for regiospecificity of the enzyme for diverse flavonoid acceptors (Hiromoto et al. 2015). The success of engineering strategies directed at altering acceptor specificity by modifying the overall volume and shape of the acceptor-binding pocket also point in this direction (Bai et al. 2016; Olsson et al. 2016; Wetterhorn et al. 2017).

A sequence-based computational tool that aims to predict GT1 function has recently been developed (Yang et al. 2018). By coupling machine learning with a comprehensive functional dataset (biochemical characterization of 54 recombinant $A$. thaliana GT1s over 17 sugar donors and 91 acceptors), algorithms were trained to predict GT1 function. This sequence-based prediction tool, GT-predict, may in future guide the curation and discovery of the burgeoning number of predicted GT1s emerging from large-scale plant genomesequencing initiatives. This tool does not, however, consider the 3D orientation of the chemical groups relative to the acceptor scaffold, and so does not take into account regiochemical biases that could sterically favor/hinder ligand binding. 
T. Louveau and A. Osbourn

A

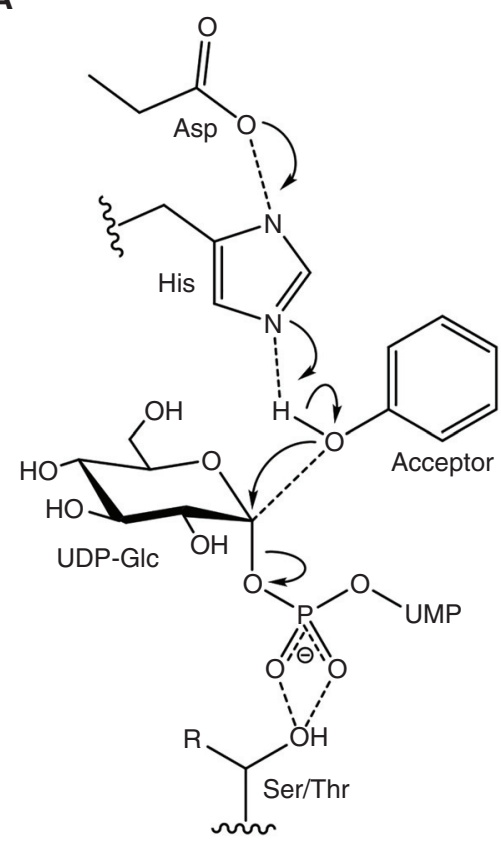

Inverting GTs: $\mathrm{S}_{\mathrm{N}}$ 2-like mechanism
B

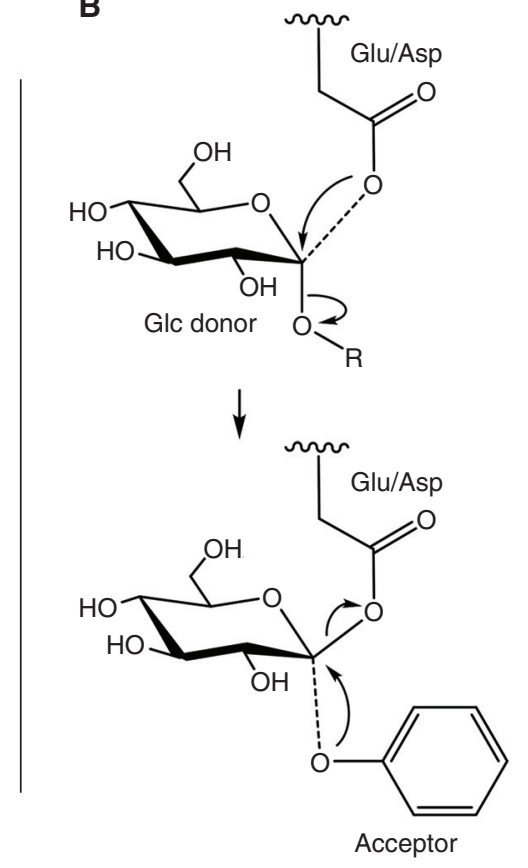

Retaining TGs: double-displacement mechanism

Figure 4. Proposed catalytic mechanisms of retaining glycosyltransferases 1 (GT1s) $(A)$ and inverting glycosyl hydrolase family 1 (GH1) transglucosidases (TGs) (B). UMP, Uridine monophosphate.

\section{SUGAR DONOR SPECIFICITY}

The sugar donor-binding pocket is located on the carboxy-terminal domain of the enzyme and is mainly composed of the PSPG motif. Highly conserved residues within the PSPG motif that interact with the UDP part of the sugar donor have been identified from crystal structures (Fig. 3). The first tryptophan (W1) in the PSPG motif forms a hydrophobic platform that stacks with the uracil ring of UDP (this residue is labeled W339 in Fig. 3B). The glutamine (Q) at the fourth position of the PSPG motif and the glutamic acid (E) at position 27 (Q342 and E365 in Fig. 3B) form hydrogen bonds with ribose hydroxyl groups. The histidine $(\mathrm{H})$ at position 19 and the serine (S) at position 24 of the PSPG motif (H357 and S362 in Fig. 3B) interact with the oxygens of the two phosphates. Two further residues of the PSPG motif (D/E43 and Q44) are implicated in sugar recognition by interacting directly with the hydroxyl groups on position C2, C3, and C4 of the sugar (Shao et al. 2005; Wang 2009).

UDP- $\alpha$-D-glucose (UDP-Glc) is the most common sugar donor recognized by GT1 enzymes. Over $80 \%$ of plant GT1 enzymes characterized so far are glucosyltransferases, and all the available crystal structures are for glucosyltransferases (Table 1). However, plant GT1 enzymes that use less common nucleotide-activated sugars have also been reported (Table 2). As mentioned earlier, sugar specificity seems to be determined by a few crucial positions, enabling rapid evolution from UDP-Glc to less common UDP-sugars. The pivotal role of the final residue of the PSPG motif for D-glucose/D-galactose selectivity has been highlighted (Table 2; Kubo et al. 2004). The replacement of the conserved Q44 by H44 determines not only galactosylation activity but also arabinosylation (Table 2; Fig. 3; Han et al. 2014; Louveau et al. 2018). Site-directed 
Plant Natural Product Glycosylation
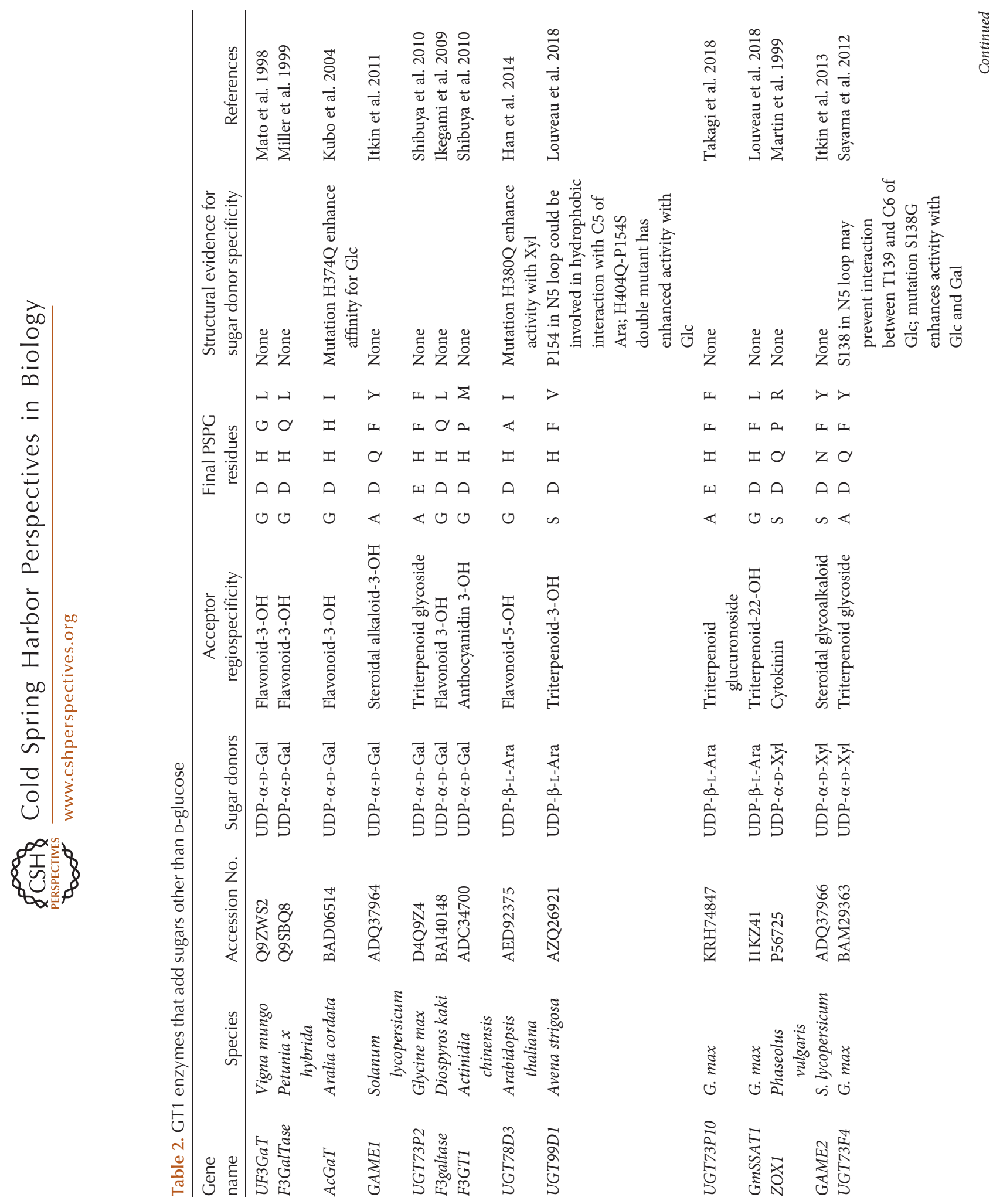
T. Louveau and A. Osbourn
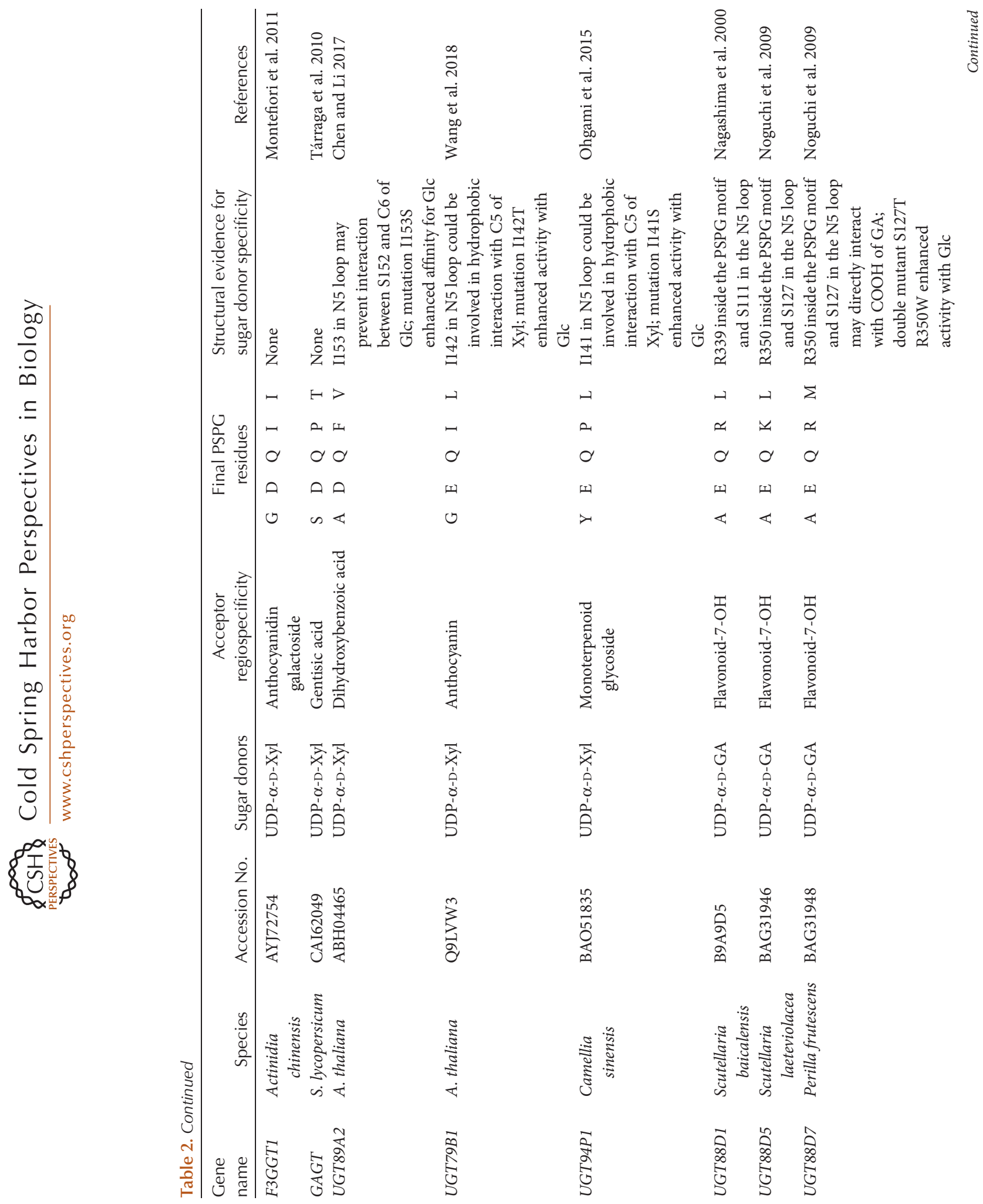

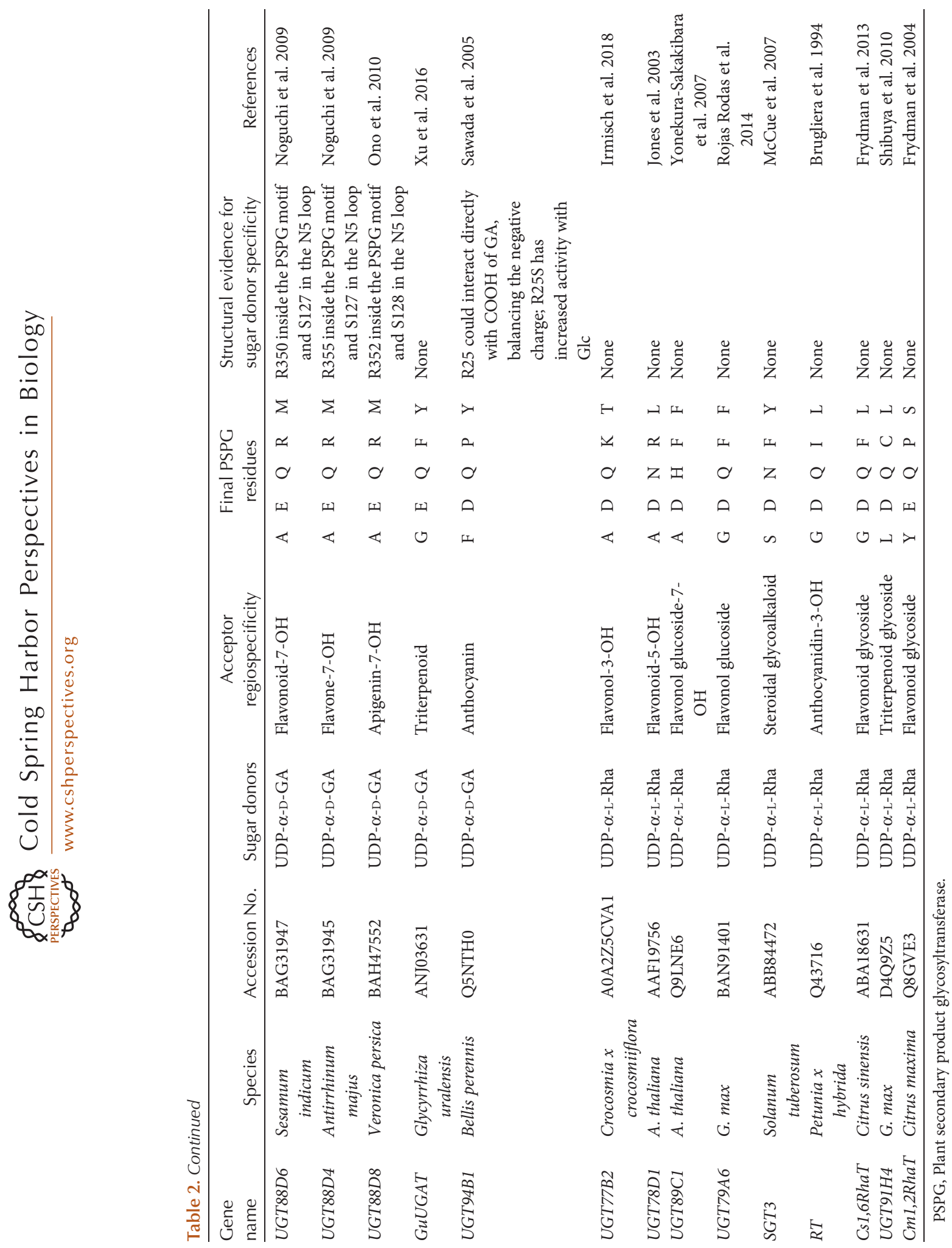
mutagenesis experiments have confirmed the importance of this residue and suggest a role in selection of the $\mathrm{C} 4$ stereochemistry (the $\mathrm{C} 4 \mathrm{hy}$ droxy of L-Ara and D-Gal being in an axial position, as opposed to the equatorial position of D-Glc C4 hydroxy; Fig. 3C). Q44 is also replaced by asparagine or histidine in some rhamnosyltransferases and xylosyltransferases but the role of these residues has not been investigated (Table 2). Characterization of xylosyltransferases has highlighted the importance of the N5 loop in sugar specificity (the fifth loop on the amino-terminal domain of GT1s, as defined by Osmani et al. 2009; Fig. 3B). Site-directed mutagenesis of xylosyltransferases and arabinosyltransferases has demonstrated the crucial role of certain residues in the N5 loop for selection between the hexoses D-glucose and D-galactose versus the corresponding structurally related pentoses, D-xylose and L-arabinose (Table 2; Fig. 3C). Crystal structures have also confirmed the proximity of the N5 loop with the D-glucose C6 hydroxy group, which is absent in pentoses (Fig. 3C) and its role in stabilizing GT1/UDPGlc conformers in VvGT1 (T141) and Os79 (S142; Table 2). The central residue of the N5 loop has also been implicated in glucuronosylation activity shown by Lamiale UGT88Ds (Table 2; Noguchi et al. 2009). Nevertheless, the prevalent determinant in glucuronosylation activity appears to be the presence of a charged residue that is able to stabilize UDP-D-glucuronic acid (UDP-GA) binding by balancing the negative charge of GA C6 carboxylate. Mutation of the arginine residues R25 and R350 of UGT94B1 and UGT88D7 (flavonoid glucuronosyltransferases from Bellis perennis and Perilla frutescens), respectively, impaired GA selectivity (Table 2).

Several plant UGT rhamnosyltransferases have been identified, but the lack of commercial sources of UDP-Rha has hindered structure/ function analysis of these enzymes. The amino acid residues that determine L-Rha recognition have not as yet been identified, although some of the residues mentioned above could be involved (Table 2). The recent report of the crystallization of $A$. thaliana rhamnosyltransferase UGT89C1 may shed light on the determinants of rhamnose specificity (Zong et al. 2019).
In summary, the recent elucidation of several GT1 crystal structures along with site-directed mutagenesis have highlighted the central role of some residues in determining sugar specificity. As seen above, two residues are particularly important in this regard: the final residue of the PSPG motif and the central residue of the N5 loop. The convergent evolution of sugar specificity implies that alternative routes exist and this is shown by the lack of $\mathrm{H} 44$ in the tomato galactosyltransferase GAME1, which initiates the addition of the $\mathrm{C} 3$ sugar chain of the steroidal glycoalkaloid $\alpha$-tomatine (Table 2 ; Itkin et al. 2011).

Enzymes capable of adding certain types of sugars that are commonly found in sugar chains of specialized metabolites (e.g., D-fucose or Dmannose) are still missing from the collection of functionally characterized GT1s from plants. However, the increasing body of knowledge about determinants of sugar specificity may enable such enzymes to be predicted based on the presence of unusual amino acid residues at specific positions that might suggest use of alternative sugar donors (nonglucose).

\section{A ROLE FOR TRANSGLYCOSIDASES IN GLYCOSYLATION OF SPECIALIZED METABOLITES IN PLANTS}

Assembly of glycosidic moieties attached to plant specialized metabolites remains poorly understood and only a limited number of enzymes that carry out such modifications have been characterized to date. Within the last 10 years, transglucosidases (TGs) have also been shown to have roles in glycosylation of small molecules. TGs have evolved from $\beta$-glucosidases belonging to the CAZY glycosyl hydrolase family 1 (GH1). GH1s are retaining glycosidases that hydrolyze glycosidic linkage via a double-displacement reaction involving a covalently bound glycosyl-enzyme intermediate (Fig. 4B; Lairson et al. 2008). GH1s usually release the sugar unit by transferring it onto a water molecule. In the case of TGs, water is replaced by a metabolite.

The TGs that have been characterized so far are scattered throughout the GH1 phylogeny 
and are more closely related to GHs than to other TGs. Modification of the transition state structures, mechanistic restriction of water access to the active site, and increased substrate specificity via binding site modifications have been proposed as factors that distinguish TGs from the prototype GH1 enzymes and promote transglycosylation activity (Bissaro et al. 2015). Plant TGs have been shown to glycosylate anthocyanins using acyl sugar substrates as sugar donors (Matsuba et al. 2010; Miyahara et al. 2012, 2014). A rice TG has also been identified that glucosylates flavonols, phytohormones, and phenylpropanoids (Luang et al. 2013).

\section{PROSPECTING FOR NEW ENZYMES AND BIOSYNTHETIC PATHWAYS}

As highlighted earlier, many glycosylated plantspecialized metabolites have important bioactive properties and a wide range of potential medicinal, agricultural, and industrial applications. The rapidly growing body of plant genome and transcriptome data (Xiao et al. 2013; Matasci et al. 2014; Kersey 2019) is opening up unprecedented opportunities to mine for genes encoding new sugar transferases to expand the glycosylation toolkit available for glycodiversification of small molecules using metabolic engineering approaches. The recent discovery that the genes for natural product pathways are sometimes organized in biosynthetic gene clusters in plant genomes is enabling the development of algorithms for prediction of new pathways encoded by suites of physically linked genes (e.g., plantiSMASH, PhytoClust), and are rapidly accelerating pathway discovery (Nützmann et al. 2016; Kautsar et al. 2017; Owen et al. 2017; Töpfer et al. 2017). The limiting factor now is not so much gene discovery as elucidation of the functions of new predicted enzymes and pathways.

\section{Engineering Plant Glycoside Biosynthesis in Heterologous Hosts}

Plant glycosides have a wealth of medicinal, agricultural, and industrial applications. Many of the plant glycosides that are currently used commercially are sourced by extraction from the pro- ducing plant species, as these compounds are too challenging to be made by synthetic chemistry, at least at commercial scale. Given that many of the source species have not been domesticated, this presents concerns about the environmental sustainability of such processes. Cell suspension or hairy root cultures are used for production of some plant natural products, including the anticancer drug taxol (Howat et al. 2014). However, these systems suffer from instability of the production lines. Furthermore, purification of the target compound is often confounded by the fact that these cultured lines often produce a plethora of isomers or related structures, making purification extremely difficult. Metabolic engineering of plant natural product pathway genes into heterologous expression systems can enable not only the recapitulation of pathways for known molecules but also the systematic glycodiversification of natural product scaffolds to generate new-to-nature compounds. Microbial systems such as the Gram-negative bacterium Escherichia coli and Baker's yeast (Saccharomyces cerevisiae) are often used as the preferred hosts for metabolic engineering of plant natural product pathways. However transient expression in the wild relative of tobacco, Nicotiana benthamiana, is now opening up new opportunities for gram-scale production of plant natural products and analogs. Some examples of glycosylated plant compounds that have been generated by metabolic engineering in these various hosts are shown in Figure 4.

E. coli only makes a limited set of sugar donors (UDP-Glc, UDP-GA, UDP-4-deoxy-4formamido-L-Ara, and TDP-sugars), which presents limitations for heterologous expression of pathways for small molecules with diverse sugars attached. An important contribution has been the engineering of $E$. coli for the production of additional sugar donors, allowing the introduction of new sugar moieties by GT1s expressed in E. coli. The Ahn laboratory has successfully produced flavonoid rhamnosides, xylosides, and arabinosides as well as flavonoids bearing other sugars, including deoxy-sugars, with yields in the region of a few hundred $\mathrm{mg} \mathrm{L}^{-1}$ (Kim et al. 2012, 2013; Yoon et al. 2012; Han et al. 2014). Other examples of plant 
glycosides produced by metabolic engineering in E. coli include indican (the direct precursor of indigo) and various phenolic glucosides (arbutin, salidroside, gastrodin; Fig. 5).

S. cerevisiae has traditionally been the host of choice for heterologous production of terpenoids and has been used successfully for the semisynthetic production of the antimalarial sesquiterpenoid drug artemisinin (Paddon and
Keasling 2014). Artemisinin is not glycosylated. However, industrial-scale production of several terpenoid glycosides has been successfully achieved in yeast, including triterpenoid glycosides known as ginsenosides, the active constituents of the herbal medicine ginseng (Mancuso and Santangelo 2017). In initial experiments the ginsenoside variants Rh1, F1, Rh2, and Rg3 (Fig. 4) accumulated at levels of $>100 \mathrm{mg} \mathrm{L}^{-1}$
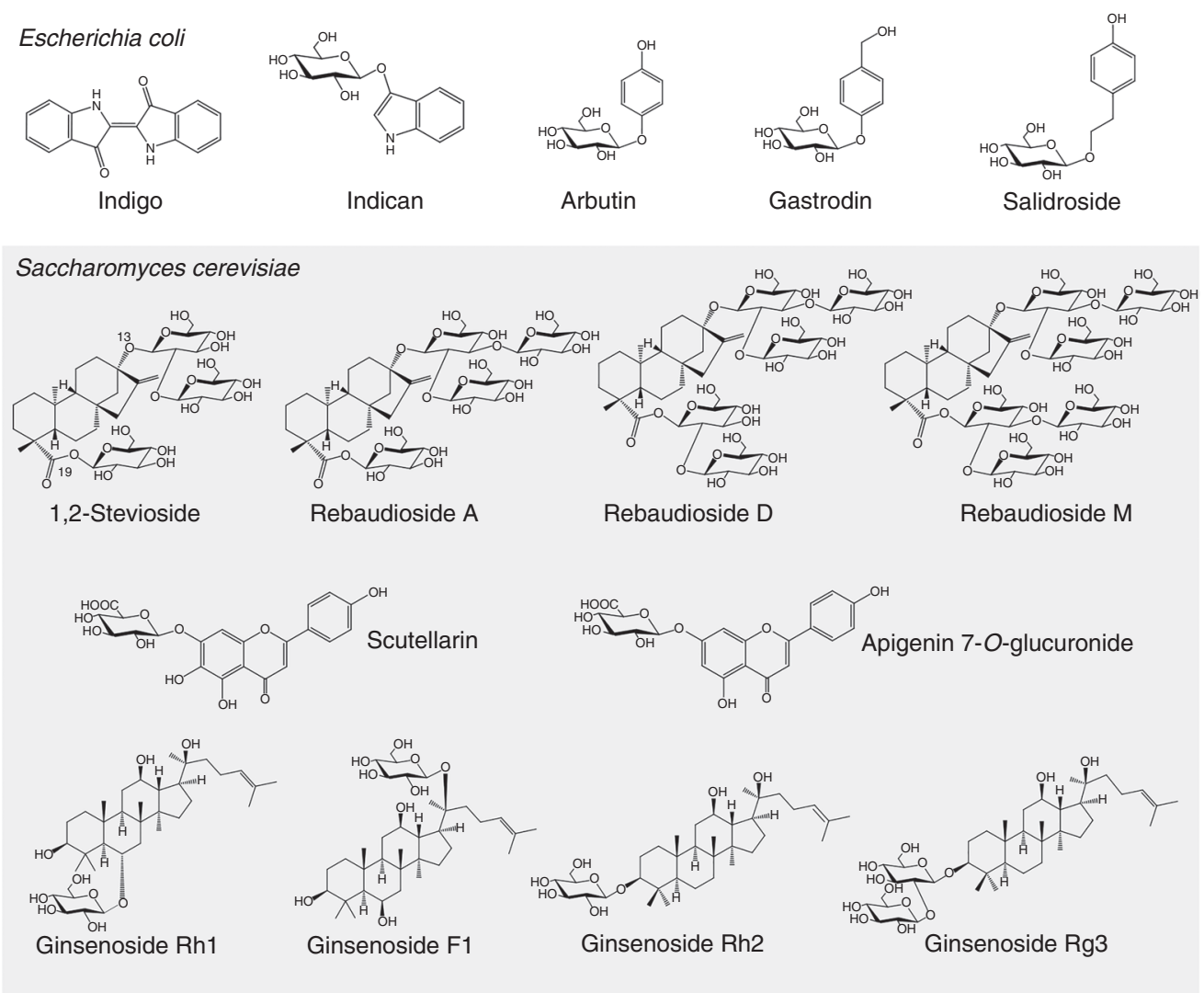

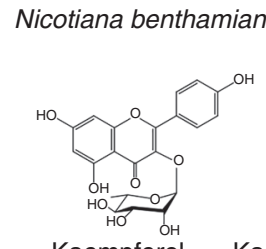

Kaempferol 3-O-rhamnoside
Kaempferol 3-O-(6'-O-coumaroyl)glucosyl rhamnoside

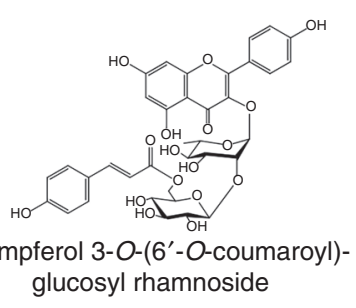

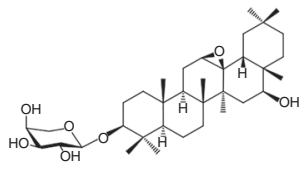

16 $\beta$-Hydroxy- $\beta$-amyrin 3-O-arabinoside

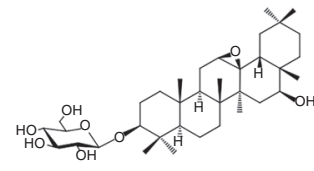

16 $\beta$-Hydroxy- $\beta$-amyrin 3-O-glucoside

Figure 5. Examples of plant glycosides produced by metabolic engineering in heterologous hosts. Examples shown are from data in Hsu et al. (2018), Shen et al. (2017), Xue et al. (2016), Chung et al. (2017), Bai et al. (2016), Louveau et al. (2018), Liu et al. (2018), Irmisch et al. (2018), Olsson et al. (2016), and Zhuang et al. (2017). 
(Jung et al. 2014; Wang et al. 2015; Wei et al. 2015). Zhuang et al. (2017) were subsequently able to achieve yields of $\sim 300 \mathrm{mg} \mathrm{L}^{-1}$ ginsenoside Rh2 in a $5 \mathrm{~L}$ bioreactor by engineering and repurposing a promiscuous yeast ergosterol GT1ScU GT51. High-throughput colorimetric screening of a mutant library enabled the catalytic efficiency of ScUGT51 to be increased by 1800-fold. These developments now offer a credible and sustainable alternative to sourcing ginsenosides from the Panax species.

There has been considerable recent interest in biotechnological approaches to produce natural sweeteners. The search for low-calorie sweeteners to reduce sucrose consumption has been driven by awareness of the risks associated with excessive calorie intake, including obesity and diabetes. Efforts have been made to understand the biosynthetic pathways for important sweeteners from plants and to engineer their production in heterologous hosts (Seki et al. 2018). Engineering of the pathway for steviol glycosides from sweetleaf (Stevia rebaudiana) (Fig. 4) currently represents the most advanced example of commercial production of natural sweeteners in yeast. Rebaudiosides D and $M$ (C19 di- and trisaccharides, respectively) are less bitter than 1,2-stevioside and rebaudioside A, the most abundant steviol glycosides found in S. rebaudiana leaves (C19 monosaccharides). A synthetic biology approach was taken to increase the ratio of rebaudiosides $\mathrm{D} / \mathrm{M}$ to 1,2-stevioside/ rebaudioside $\mathrm{A}$ in yeast. This was achieved by targeted optimization of one of the GT1s required for steviol glycoside biosynthesis to reshape the acceptor-binding site, and therefore modulating acceptor accommodation (Olsson et al. 2016). This work, as well as further pathway optimization (U.S. Patent No. 9,957,540 B2), allows improved production of rebaudioside $\mathrm{D} / \mathrm{M}$ and reduced accumulation of undesirable bitter steviosides in yeast. These improved Stevia sweeteners (developed by the company Evolva) have been sold commercially under the brand name EverSweet since March 2018.

D-Glucose is readily available in yeast and most of the work reported here has involved the production of glucosides. However, efforts to engineer alternative UDP sugar pathways into yeast have also been undertaken. Liu et al. (2018) recently reported the production of two flavonoid glucuronosides, including $108 \mathrm{mg} \mathrm{L}^{-1}$ of scutellarin and $185 \mathrm{mg} \mathrm{L}^{-1}$ of apigenin 7-O-glucuronide in yeast (Fig. 4). Metabolic engineering was undertaken to increase the pull of malonylCoA (a phenylpropanoid precursor) as well as to provide the required sugar donor UDP-galactose via expression of the UDP-glucose dehydrogenase from the Chinese plant Erigeron breviscapus.

Plants have a number of advantages as hosts for heterologous expression of enzymes and pathways of plant origin. There is no need for sequence recoding, they support correct messenger RNA (mRNA) and protein processing, protein localization, and metabolic compartmentalization, and have many of the necessary metabolic precursors and coenzymes. Transient expression in $N$. benthamiana is proving to be a very rapid and powerful method for metabolic engineering of plant natural product pathways (Reed et al. 2017; Reed and Osbourn 2018; Stephenson et al. 2018). This method involves infiltrating Agrobacterium tumefaciens containing expression constructs for the genes of interest into N. benthamiana leaves. This system is also eminently scalable and is currently being used for commercial production of flu vaccines (Marsian and Lomonossoff 2016). The process takes only 5-6 days from agroinfiltration to extraction of plant tissue. Furthermore, combinations of genes can be expressed together simply by coinfiltrating multiple $A$. tumefaciens strains containing different expression constructs (Lau and Sattely 2015; Reed and Osbourn 2018). Transient plant expression has been used to generate gram-scale quantities of pure triterpenoid and is highly amenable to metabolic engineering of more complex glycosides.

Production of triterpenoid glucosides (Khakimov et al. 2015; Louveau et al. 2018), cyanogenic glycosides (Takos et al. 2011), and glucosinolates (Geu-Flores et al. 2009; Pfalz et al. 2011; Crocoll et al. 2016) have been reported in N. benthamiana. This platform is particularly attractive for production of complex glycosides. Recent publications have confirmed the amenability of $N$. benthamiana for heterologous pro- 
duction of metabolites conjugated to various sugar units. The production of triterpenoid arabinosides, xylosides, and galactosides as well as flavonoid rhamnosides has been reported (Fig. 5; Irmisch et al. 2018; Louveau et al. 2018).

\section{CONCLUDING REMARKS}

As we have seen in this review, glycosidic moieties impact substantially on the bioactivity and bioavailability of plant specialized metabolites. By harnessing an array of plant GT enzymes that are able to add single and multiple sugars, it should be possible in the future to carry out systematic glycodiversification of small molecule scaffolds. This will be facilitated by the ever-growing amount of available plant genome and transcriptome data, the development and refinement of algorithms that enable the discovery of new sugar transferase enzymes, and by synthetic biology (e.g., DNA synthesis, standardization of parts, modular cloning systems) (Owen et al. 2017). Better understanding of the structure/activity relationships of plant GTs will enable rational design of new biocatalysts. These advances, in combination with optimized microbial and plant heterologous expression platforms and the advanced tools offered by modern molecular biology (e.g., affordable synthetic genes, standardization of DNA assembly technologies, CRISPR) have the potential to drive the development of a new generation of biobased pharmaceuticals, food additives, personal care products, agrichemicals, and other industrially important compounds.

\section{ACKNOWLEDGMENTS}

We acknowledge the support of the Biotechnological and Biological Sciences-funded Institute Strategic Programme Grant "Molecules from Nature" (BB/P012523/1) and the John Innes Foundation.

\section{REFERENCES}

Achnine L, Huhman DV, Farag MA, Sumner LW, Blount JW, Dixon RA. 2005. Genomics-based selection and functional characterization of triterpene glycosyltransfer- ases from the model legume Medicago truncatula. Plant $J$ 41: 875-887. doi:10.1111/j.1365-313X.2005.02344.x

Afendi FM, Okada T, Yamazaki M, Hirai-Morita A, Nakamura Y, Nakamura K, Ikeda S, Takahashi H, Altaf-UlAmin M, Darusman LK, et al. 2012. KNApSAcK family databases: integrated metabolite-plant species databases for multifaceted plant research. Plant Cell Physiol 53: e1. doi:10.1093/pcp/pcr165

Augustin JM, Kuzina V, Andersen SB, Bak S. 2011. Molecular activities, biosynthesis and evolution of triterpenoid saponins. Phytochemistry 72: 435-457. doi:10.1016/j .phytochem.2011.01.015

Bai Y, Yin H, Bi H, Zhuang Y, Liu T, Ma Y. 2016. De novo biosynthesis of gastrodin in Escherichia coli. Metab Eng 35: 138-147. doi:10.1016/j.ymben.2016.01.002

Bissaro B, Monsan P, Fauré R, O’Donohue MJ. 2015. Glycosynthesis in a waterworld: New insight into the molecular basis of transglycosylation in retaining glycoside hydrolases. Biochem J 467: 17-35. doi:10.1042/BJ20141412

Bowles D, Lim EK, Poppenberger B, Vaistij FE. 2006. Glycosyltransferases of lipophilic small molecules. Annu Rev Plant Biol 57: 567-597. doi:10.1146/annurev.arplant.57 .032905 .105429

Bowyer P, Clarke BR, Lunness P, Daniels MJ, Osbourn AE. 1995. Host range of a plant pathogenic fungus determined by a saponin detoxifying enzyme. Science 267 : 371-374. doi:10.1126/science.7824933

Brazier-Hicks M, Offen WA, Gershater MC, Revett TJ, Lim EK, Bowles DJ, Davies GJ, Edwards R. 2007a. Characterization and engineering of the bifunctional $\mathrm{N}$ - and $\mathrm{O}$ glucosyltransferase involved in xenobiotic metabolism in plants. Proc Natl Acad Sci 104: 20238-20243. doi:10 $.1073 /$ pnas.0706421104

Brazier-Hicks M, Edwards LA, Edwards R. 2007b. Selection of plants for roles in phytoremediation: The importance of glucosylation. Plant Biotechnol J 5: 627-635.

Brazier-Hicks M, Gershater M, Dixon D, Edwards R. 2018. Substrate specificity and safener inducibility of the plant UDP-glucose-dependent family 1 glycosyltransferase super-family. Plant Biotechnol J 16: 337-348. doi:10.1111/ pbi. 12775

Brugliera F, Holton TA, Stevenson TW, Farcy E, Lu CY, Cornish EC. 1994. Isolation and characterization of a cDNA clone corresponding to the Rt locus of Petunia hybrida. Plant J 5: 81-92. doi:10.1046/j.1365-313X.1994 $.5010081 . \mathrm{x}$

Cantarel BL, Coutinho PM, Rancurel C, Bernard T, Lombard V, Henrissat B. 2009. The carbohydrate-active enzymes database (CAZy): An expert resource for glycogenomics. Nucleic Acids Res 37: D233-D238. doi:10.1093/nar/ gkn663

Caputi L, Lim EK, Bowles DJ. 2008. Discovery of new biocatalysts for the glycosylation of terpenoid scaffolds. Chemistry 14: 6656-6662. doi:10.1002/chem.200800548

Caputi L, Malnoy M, Goremykin V, Nikiforova S, Martens S. 2012. A genome-wide phylogenetic reconstruction of family 1 UDP-glycosyltransferases revealed the expansion of the family during the adaptation of plants to life on land. Plant J 69: 1030-1042. doi:10.1111/j.1365-313X .2011.04853.x

Chen HY, Li X. 2017. Identification of a residue responsible for UDP-sugar donor selectivity of a dihydroxybenzoic 
acid glycosyltransferase from Arabidopsis natural accessions. Plant J 89: 195-203. doi:10.1111/tpj.13271

Chung D, Kim SY, Ahn JH. 2017. Production of three phenylethanoids, tyrosol, hydroxytyrosol, and salidroside, using plant genes expressing in Escherichia coli. Sci Rep 7: 2578. doi:10.1038/s41598-017-02042-2

Crocoll C, Mirza N, Reichelt M, Gershenzon J, Halkier BA. 2016. Optimization of engineered production of the glucoraphanin precursor dihomomethionine in Nicotiana benthamiana. Front Bioeng Biotechnol 4: 14. doi:10 .3389/fbioe.2016.00014.

de Bruijn WJC, Gruppen H, Vincken JP. 2018. Structure and biosynthesis of benzoxazinoids: Plant defence metabolites with potential as antimicrobial scaffolds. Phytochemistry 155: 233-243. doi:10.1016/j.phytochem.2018.07.005

Edgar RC. 2004. MUSCLE: A multiple sequence alignment method with reduced time and space complexity. $B M C$ Bioinformatics 5: 113. doi:10.1186/1471-2105-5-113

Frydman A, Weisshaus O, Bar-Peled M, Huhman DV, Sumner LW, Marin FR, Lewinsohn E, Fluhr R, Gressel J, Eyal Y. 2004. Citrus fruit bitter flavors: Isolation and functional characterization of the gene Cm1,2RhaT encoding a 1,2 rhamnosyltransferase, a key enzyme in the biosynthesis of the bitter flavonoids of citrus. Plant J 40: 88-100. doi:10 $.1111 / \mathrm{j} .1365-313 X .2004 .02193 . x$

Frydman A, Liberman R, Huhman DV, Carmeli-Weissberg M, Sapir-Mir M, Ophir R, Sumner LW, Eyal Y. 2013. The molecular and enzymatic basis of bitter/non-bitter flavor of citrus fruit: Evolution of branch-forming rhamnosyltransferases under domestication. Plant J 73: 166-178. doi:10.1111/tpj.12030

George Thompson AM, Iancu CV, Neet KE, Dean JV, Choe JY. 2017. Differences in salicylic acid glucose conjugations by UGT74F1 and UGT74F2 from Arabidopsis thaliana. Sci Rep 7: 46629. doi:10.1038/srep46629

Geu-Flores F, Nielsen MT, Nafisi M, Møldrup ME, Olsen CE, Motawia MS, Halkier BA. 2009. Glucosinolate engineering identifies a $\gamma$-glutamyl peptidase. Nat Chem Biol 5: 575-577.

Gleadow RM, Møller BL. 2014. Cyanogenic glycosides: Synthesis, physiology, and phenotypic plasticity. Annu Rev Plant Biol 65: 155-185. doi:10.1146/annurev-arplant050213-040027

Grubb CD, Zipp BJ, Ludwig-Müller J, Masuno MN, Molinski TF, Abel S. 2004. Arabidopsis glucosyltransferase UGT74B1 functions in glucosinolate biosynthesis and auxin homeostasis. Plant J 40: 893-908.

Han SH, Kim BG, Yoon JA, Chong Y, Ahn JH. 2014. Synthesis of flavonoid O-pentosides by Escherichia col through engineering of nucleotide sugar pathways and glycosyltransferase. Appl Environ Microbiol 80: 27542762. doi:10.1128/AEM.03797-13

He XZ, Wang X, Dixon RA. 2006. Mutational analysis of the Medicago glycosyltransferase UGT71G1 reveals residues that control regioselectivity for (iso)flavonoid glycosylation. J Biol Chem 281: 34441-34447. doi:10.1074/jbc .M605767200

Hiromoto T, Honjo E, Noda N, Tamada T, Kazuma K, Suzuki M, Blaber M, Kuroki R. 2015. Structural basis for acceptor-substrate recognition of UDP-glucose: Anthocyanidin 3-O-glucosyltransferase from Clitoria ternatea. Protein Sci 24: 395-407. doi:10.1002/pro.2630
Hopkins RJ, van Dam NM, van Loon JJ. 2009. Role of glucosinolates in insect-plant relationships and multitrophic interactions. Annu Rev Entomol 54: 57-83. doi:10.1146/ annurev.ento.54.110807.090623

Hou B, Lim EK, Higgins GS, Bowles DJ. 2004. N-glucosylation of cytokinins by glycosyltransferases of Arabidopsis thaliana. J Biol Chem 279: 47822-47832.

Howat S, Park B, Oh IS, Jin YW, Lee EK, Loake GJ. 2014. Paclitaxel: Biosynthesis, production and future prospects. N Biotechnol 31: 242-245. doi:10.1016/j.nbt.2014.02.010

Howe GA, Jander G. 2008. Plant immunity to insect herbivores. Annu Rev Plant Biol 59: 41-66. doi:10.1146/an nurev.arplant.59.032607.092825

Hsu TM, Welner DH, Russ ZN, Cervantes B, Prathuri RL, Adams PD, Dueber JE. 2018. Employing a biochemical protecting group for a sustainable indigo dyeing strategy. Nat Chem Biol 14: 256-261. doi:10.1038/nchembio.2552

Hughes J, Hughes MA. 1994. Multiple secondary plant product UDP-glucose glucosyltransferase genes expressed in cassava (Manihot esculenta Crantz) cotyledons. DNA Seq 5: 41-49. doi:10.3109/104251794090 39703

Ikegami A, Akagi T, Potter D, Yamada M, Sato A, Yonemori K, Kitajima A, Inoue K. 2009. Molecular identification of 1-Cys peroxiredoxin and anthocyanidin/flavonol 3-Ogalactosyltransferase from proanthocyanidin-rich young fruits of persimmon (Diospyros kaki Thunb.). Planta 230: 841-855. doi:10.1007/s00425-009-0989-0

Irmisch S, Jo S, Roach CR, Jancsik S, Man Saint Yuen M, Madilao LL, O'Neil-Johnson M, Williams R, Withers SG, Bohlmann J. 2018. Discovery of UDP-glycosyltransferases and BAHD-acyltransferases involved in the biosynthesis of the antidiabetic plant metabolite montbretin A. Plant Cell 30: 1864-1886. doi:10.1105/tpc.18.00406

Itkin M, Rogachev I, Alkan N, Rosenberg T, Malitsky S, Masini L, Meir S, Iijima Y, Aoki K, de Vos R, et al. 2011. GLYCOALKALOID METABOLISM1 is required for steroidal alkaloid glycosylation and prevention of phytotoxicity in tomato. Plant Cell 23: 4507-4525. doi:10 $.1105 /$ tpc.111.088732

Itkin M, Heinig U, Tzfadia O, Bhide AJ, Shinde B, Cardenas PD, Bocobza SE, Unger T, Malitsky S, Finkers R, et al. 2013. Biosynthesis of antinutritional alkaloids in solanaceous crops is mediated by clustered genes. Science 341: 175-179. doi:10.1126/science.1240230

Jones P, Vogt T. 2001. Glycosyltransferases in secondary plant metabolism: Tranquilizers and stimulant controllers. Planta 213: 164-174.

Jones P, Messner B, Nakajima J, Schaffner AR, Saito K. 2003. UGT73C6 and UGT78D1, glycosyltransferases involved in flavonol glycoside biosynthesis in Arabidopsis thaliana. J Biol Chem 278: 43910-43918. doi:10.1074/jbc .M303523200

Jung SC, Kim W, Park SC, Jeong J, Park MK, Lim S, Lee Y, Im WT, Lee JH, Choi G, et al. 2014. Two ginseng UDP glycosyltransferases synthesize ginsenoside $\mathrm{Rg} 3$ and $\mathrm{Rd}$. Plant Cell Physiol 55: 2177-2188. doi:10.1093/pcp/ pcu147

Kannangara R, Motawia MS, Hansen NK, Paquette SM, Olsen CE, Moller BL, Jorgensen K. 2011. Characterization and expression profile of two UDP-glucosyltransferases, UGT85K4 and UGT85K5, catalyzing the last step in cy- 
T. Louveau and A. Osbourn

anogenic glucoside biosynthesis in cassava. Plant $J$ 68: 287-301. doi:10.1111/j.1365-313X.2011.04695.x

Kautsar SA, Suarez Duran HG, Blin K, Osbourn A, Medema MH. 2017. PlantiSMASH: automated identification, annotation and expression analysis of plant biosynthetic gene clusters. Nucleic Acids Res 45: W55-W63. doi:10 $.1093 /$ nar/gkx305

Kersey PJ. 2019. Plant genome sequences: Past, present, future. Curr Opin Plant Biol 48: 1-8. doi:10.1016/j.pbi.2018 .11 .001

Khakimov B, Kuzina V, Erthmann PO, Fukushima EO, Augustin JM, Olsen CE, Scholtalbers J, Volpin H, Andersen SB, Hauser TP, et al. 2015. Identification and genome organization of saponin pathway genes from a wild crucifer, and their use for transient production of saponins in Nicotiana benthamiana. Plant J 84: 478-490. doi:10 $.1111 /$ tpj.13012

Kim BG, Kim HJ, Ahn JH. 2012. Production of bioactive flavonol rhamnosides by expression of plant genes in Escherichia coli. J Agric Food Chem 60: 11143-11148. doi:10.1021/jf302123c

Kim HJ, Kim BG, Ahn JH. 2013. Regioselective synthesis of flavonoid bisglycosides using Escherichia coli harboring two glycosyltransferases. Appl Microbiol Biotechnol 97: 5275-5282. doi:10.1007/s00253-013-4844-7

Kubo A, Arai Y, Nagashima S, Yoshikawa T. 2004. Alteration of sugar donor specificities of plant glycosyltransferases by a single point mutation. Arch Biochem Biophys 429: 198-203. doi:10.1016/j.abb.2004.06.021

Lairson LL, Henrissat B, Davies GJ, Withers SG. 2008. Glycosyltransferases: structures, functions, and mechanisms. Annu Rev Biochem 77: 521-555. doi:10.1146/annurev .biochem.76.061005.092322

Lau W, Sattely ES. 2015. Six enzymes from mayapple that complete the biosynthetic pathway to the etoposide aglycone. Science 349: 1224-1228. doi:10.1126/science .aac7202

Li L, Modolo LV, Escamilla-Trevino LL, Achnine L, Dixon RA, Wang X. 2007. Crystal structure of Medicago truncatula UGT85H2-insights into the structural basis of a multifunctional (iso)flavonoid glycosyltransferase. J Mol Biol 370: 951-963. doi:10.1016/j.jmb.2007.05.036

Li Y, Li P, Wang Y, Dong R, Yu H, Hou B. 2014. Genomewide identification and phylogenetic analysis of Family-1 UDP glycosyltransferases in maize (Zea mays). Planta 239: 1265-1279. doi:10.1007/s00425-014-2050-1

Lim EK, Doucet CJ, Li Y, Elias L, Worrall D, Spencer SP, Ross J, Bowles DJ. 2002. The activity of Arabidopsis glycosyltransferases toward salicylic acid, 4-hydroxybenzoic acid, and other benzoates. J Biol Chem 277: 586-592. doi:10 $.1074 /$ jbc.M109287200

Lim EK, Ashford DA, Hou B, Jackson RG, Bowles DJ. 2004. Arabidopsis glycosyltransferases as biocatalysts in fermentation for regioselective synthesis of diverse quercetin glucosides. Biotechnol Bioeng 87: 623-631. doi:10.1002/ bit.20154

Liu X, Cheng J, Zhang G, Ding W, Duan L, Yang J, Kui L, Cheng X, Ruan J, Fan W, et al. 2018. Engineering yeast for the production of breviscapine by genomic analysis and synthetic biology approaches. Nat Commun 9: 448. doi:10.1038/s41467-018-02883-Z
Louveau T, Orme A, Pfalzgraf H, Stephenson MJ, Melton R, Saalbach G, Hemmings AM, Leveau A, Rejzek M, Vickerstaff RJ, et al. 2018. Analysis of two new arabinosyltransferases belonging to the carbohydrate-active enzyme (CAZY) glycosyl transferase family1 provides insights into disease resistance and sugar donor specificity. Plant Cell 30: 3038-3057. doi:10.1105/tpc.18.00641

Luang S, Cho JI, Mahong B, Opassiri R, Akiyama T, Phasai K, Komvongsa J, Sasaki N, Hua YL, Matsuba Y, et al. 2013. Rice Os9BGlu31 is a transglucosidase with the capacity to equilibrate phenylpropanoid, flavonoid, and phytohormone glycoconjugates. J Biol Chem 288: 10111-10123. doi:10.1074/jbc.M112.423533

Mancuso C, Santangelo R. 2017. Panax ginseng and Panax quinquefolius: From pharmacology to toxicology. Food Chem Toxicol 107: 362-372. doi:10.1016/j.fct.2017.07 .019

Marsian J, Lomonossoff GP. 2016. Molecular pharmingVLPs made in plants. Curr Opin Biotechnol 37: 201-206. doi:10.1016/j.copbio.2015.12.007

Martin RC, Mok MC, Mok DW. 1999. A gene encoding the cytokinin enzyme zeatin $O$-xylosyltransferase of Phaseolus vulgaris. Plant Physiol 120: 553-558. doi:10.1104/pp .120 .2 .553

Matasci N, Hung LH, Yan Z, Carpenter EJ, Wickett NJ, Mirarab S, Nguyen N, Warnow T, Ayyampalayam S, Barker M, et al. 2014. Data access for the 1,000 Plants (1KP) project. Gigascience 3: 17. doi:10.1186/2047-217X-3-17

Mato M, Ozeki Y, Itoh Y, Higeta D, Yoshitama K, Teramoto S, Aida R, Ishikura N, Shibata M. 1998. Isolation and characterization of a cDNA clone of UDP-galactose: Flavonoid 3-O-galactosyltransferase (UF3GaT) expressed in Vigna mungo seedlings. Plant Cell Physiol 39: 1145-1155. doi:10.1093/oxfordjournals.pcp.a029315

Matsuba Y, Sasaki N, Tera M, Okamura M, Abe Y, Okamoto E, Nakamura H, Funabashi H, Takatsu M, Saito M, et al. 2010. A novel glucosylation reaction on anthocyanins catalyzed by acyl-glucose-dependent glucosyltransferase in the petals of carnation and delphinium. Plant Cell 22: 3374-3389. doi:10.1105/tpc.110.077487

McCue KF, Allen PV, Shepherd LV, Blake A, Maccree MM, Rockhold DR, Novy RG, Stewart D, Davies HV, Belknap WR. 2007. Potato glycosterol rhamnosyltransferase, the terminal step in triose side-chain biosynthesis. Phytochemistry 68: 327-334. doi:10.1016/j.phytochem.2006 .10 .025

Miller KD, Guyon V, Evans JN, Shuttleworth WA, Taylor LP. 1999. Purification, cloning, and heterologous expression of a catalytically efficient flavonol 3-O-galactosyltransferase expressed in the male gametophyte of Petunia hybrida. J Biol Chem 274: 34011-34019. doi:10.1074/jbc .274.48.34011

Miyahara T, Takahashi M, Ozeki Y, Sasaki N. 2012. Isolation of an acyl-glucose-dependent anthocyanin 7-O-glucosyltransferase from the monocot Agapanthus africanus. J Plant Physiol 169: 1321-1326. doi:10.1016/j.jplph.2012 .05 .004

Miyahara T, Tani T, Takahashi M, Nishizaki Y, Ozeki Y, Sasaki N. 2014. Isolation of anthocyanin 7-O-glucosyltransferase from Canterbury bells (Campanula medium). Plant Biotechnol 31: 555-559. doi:10.5511/plantbiotech nology.14.0908a 
Modolo LV, Li L, Pan H, Blount JW, Dixon RA, Wang X. 2009. Crystal structures of glycosyltransferase UGT78G1 reveal the molecular basis for glycosylation and deglycosylation of (iso)flavonoids. J Mol Biol 392: 1292-1302. doi:10.1016/j.jmb.2009.08.017

Mohamed AA, Ceunen S, Geuns JM, Van den Ende W, De Ley M. 2011. UDP-dependent glycosyltransferases involved in the biosynthesis of steviol glycosides. J Plant Physiol 168: 1136-1141. doi:10.1016/j.jplph.2011.01.030

Montefiori M, Espley RV, Stevenson D, Cooney J, Datson PM, Saiz A, Atkinson RG, Hellens RP, Allan AC. 2011 Identification and characterisation of F3GT1 and F3GGT1, two glycosyltransferases responsible for anthocyanin biosynthesis in red-fleshed kiwifruit (Actinidia chinensis). Plant J 65: 106-118. doi:10.1111/j.1365-313X 2010.04409.x

Nagashima S, Hirotani M, Yoshikawa T. 2000. Purification and characterization of UDP-glucuronate: Baicalein 7 O-glucuronosyltransferase from Scutellaria baicalensis Georgi. cell suspension cultures. Phytochemistry 53: 533-538. doi:10.1016/S0031-9422(99)00593-2

Nagatomo Y, Usui S, Ito T, Kato A, Shimosaka M, Taguchi G. 2014. Purification, molecular cloning and functional characterization of flavonoid $C$-glucosyltransferases from Fagopyrum esculentum M. (buckwheat) cotyledon. Plant J 80: 437-448. doi:10.1111/tpj.12645

Nagatoshi M, Terasaka K, Nagatsu A, Mizukami H. 2011. Iridoid-specific glucosyltransferase from Gardenia jasminoides. J Biol Chem 286: 32866-32874. doi:10.1074/jbc .M111.242586

Noda N. 2018. Recent advances in the research and development of blue flowers. Breed Sci 68: 79-87. doi:10.1270/ jsbbs. 17132

Noda N, Yoshioka S, Kishimoto S, Nakayama M, Douzono M, Tanaka Y, Aida R. 2017. Generation of blue chrysanthemums by anthocyanin B-ring hydroxylation and glucosylation and its coloration mechanism. Sci Adv 3: e1602785. doi:10.1126/sciadv.1602785

Noguchi A, Saito A, Homma Y, Nakao M, Sasaki N, Nishino T, Takahashi S, Nakayama T. 2007. A UDP-glucose:isoflavone 7-O-glucosyltransferase from the roots of soybean (Glycine max) seedlings. Purification, gene cloning, phylogenetics, and an implication for an alternative strategy of enzyme catalysis. J Biol Chem 282: 23581-23590. doi:10.1074/jbc.M702651200

Noguchi A, Horikawa M, Fukui Y, Fukuchi-Mizutani M, Iuchi-Okada $\mathrm{A}$, Ishiguro $\mathrm{M}$, Kiso $\mathrm{Y}$, Nakayama T, Ono E. 2009. Local differentiation of sugar donor specificity of flavonoid glycosyltransferase in Lamiales. Plant Cell 21: 1556-1572. doi:10.1105/tpc.108.063826

Nuccio ML, Rhodes D, McNeil SD, Hanson AD. 1999. Metabolic engineering of plants for osmotic stress resistance. Curr Opin Plant Biol 2: 128-134. doi:10.1016/S1369-5266 (99) $80026-0$

Nützmann HW, Huang A, Osbourn A. 2016. Plant metabolic clusters-From genetics to genomics. New Phytol 211: 771-789. doi:10.1111/nph.13981

Offen W, Martinez-Fleites C, Yang M, Kiat-Lim E, Davis BG, Tarling CA, Ford CM, Bowles DJ, Davies GJ. 2006. Structure of a flavonoid glucosyltransferase reveals the basis for plant natural product modification. EMBO J 25: $1396-$ 1405. doi:10.1038/sj.emboj. 7600970
Ogata J, Kanno Y, Itoh Y, Tsugawa H, Suzuki M. 2005. Plant biochemistry: Anthocyanin biosynthesis in roses. Nature 435: 757-758. doi:10.1038/nature435757a

Ohgami S, Ono E, Horikawa M, Murata J, Totsuka K, Toyonaga $\mathrm{H}$, Ohba Y, Dohra H, Asai T, Matsui K, et al. 2015. Volatile glycosylation in tea plants: Sequential glycosylations for the biosynthesis of aroma $\beta$-primeverosides are catalyzed by two Camellia sinensis glycosyltransferases. Plant Physiol 168: 464-477. doi:10.1104/pp.15.00403

Oldroyd GE. 2013. Speak, friend, and enter: Signalling systems that promote beneficial symbiotic associations in plants. Nat Rev Microbiol 11: 252-263. doi:10.1038/nrmi cro2990

Olsson K, Carlsen S, Semmler A, Simon E, Mikkelsen MD, Moller BL. 2016. Microbial production of next-generation stevia sweeteners. Microb Cell Fact 15: 207. doi:10.1186/ s12934-016-0609-1

Ono E, Ruike M, Iwashita T, Nomoto K, Fukui Y. 2010. Copigmentation and flavonoid glycosyltransferases in blue Veronica persica flowers. Phytochemistry 71: 726-735. doi:10.1016/j.phytochem.2010.02.008

Osbourn A. 1996. Saponins and plant defense-A soap story. Trends Plant Sci 1: 4-9. doi:10.1016/S1360-1385(96) 80016-1

Osmani SA, Bak S, Møller BL. 2009. Substrate specificity of plant UDP-dependent glycosyltransferases predicted from crystal structures and homology modeling. Phytochemistry 70: 325-347. doi:10.1016/j.phytochem.2008.12 .009

Owen C, Patron NJ, Huang A, Osbourn A. 2017. Harnessing plant metabolic diversity. Curr Opin Chem Biol 40: 24-30. doi:10.1016/j.cbpa.2017.04.015

Paddon CJ, Keasling JD. 2014. Semi-synthetic artemisinin: A model for the use of synthetic biology in pharmaceutical development. Nat Rev Microbiol 12: 355-367. doi:10 $.1038 /$ nrmicro3240

Pfalz M, Mikkelsen MD, Bednarek P, Olsen CE, Halkier BA, Kroymann J. 2011. Metabolic engineering in Nicotiana benthamiana reveals key enzyme functions in Arabidopsis indole glucosinolate modification. Plant Cell 23: 716-729.

Piotrowska A, Bajguz A. 2011. Conjugates of abscisic acid, brassinosteroids, ethylene, gibberellins, and jasmonates. Phytochemistry 72: 2097-2112. doi:10.1016/j.phytochem .2011 .08 .012

Reed J, Osbourn A. 2018. Engineering terpenoid production through transient expression in Nicotiana benthamiana. Plant Cell Rep 37: 1431-1441. doi:10.1007/s00299-0182296-3

Reed J, Stephenson MJ, Miettinen K, Brouwer B, Leveau A, Brett P, Goss RJM, Goossens A, O'Connell MA, Osbourn A. 2017. A translational synthetic biology platform for rapid access to gram-scale quantities of novel drug-like molecules. Metab Eng 42: 185-193. doi:10.1016/j.ymben .2017 .06 .012

Rojas Rodas F, Rodriguez TO, Murai Y, Iwashina T, Sugawara S, Suzuki M, Nakabayashi R, Yonekura-Sakakibara K, Saito K, Kitajima J, et al. 2014. Linkage mapping, molecular cloning and functional analysis of soybean gene $\mathrm{Fg} 2$ encoding flavonol 3-O-glucoside $(1 \rightarrow 6)$ rhamnosyltransferase. Plant Mol Biol 84: 287-300. doi:10.1007/ s11103-013-0133-1 
Ross J, Li Y, Lim E, Bowles DJ. 2001. Higher plant glycosyltransferases. Genome Biol 2: reviews3004.30013004.3006. doi:10.1186/gb-2001-2-2-reviews3004

Sawada S, Suzuki H, Ichimaida F, Yamaguchi MA, Iwashita T, Fukui Y, Hemmi H, Nishino T, Nakayama T. 2005. UDP-glucuronic acid:anthocyanin glucuronosyltransferase from red daisy (Bellis perennis) flowers. Enzymology and phylogenetics of a novel glucuronosyltransferase involved in flower pigment biosynthesis. J Biol Chem 280: 899-906. doi:10.1074/jbc.M410537200

Sawai S, Saito K. 2011. Triterpenoid biosynthesis and engineering in plants. Front Plant Sci 2: 25. doi:10.3389/fpls .2011 .00025

Sayama T, Ono E, Takagi K, Takada Y, Horikawa M, Nakamoto Y, Hirose A, Sasama H, Ohashi M, Hasegawa H, et al. 2012. The $S g$-1 glycosyltransferase locus regulates structural diversity of triterpenoid saponins of soybean. Plant Cell 24: 2123-2138. doi:10.1105/tpc.111.095174

Seki H, Tamura K, Muranaka T. 2018. Plant-derived isoprenoid sweeteners: Recent progress in biosynthetic gene discovery and perspectives on microbial production. Biosci Biotechnol Biochem 82: 927-934. doi:10.1080/ 09168451.2017.1387514

Shao H, He X, Achnine L, Blount JW, Dixon RA, Wang X. 2005. Crystal structures of a multifunctional triterpene/ flavonoid glycosyltransferase from Medicago truncatula. Plant Cell 17: 3141-3154. doi:10.1105/tpc.105.035055

Shen X, Wang J, Wang J, Chen Z, Yuan Q, Yan Y. 2017. High-level De novo biosynthesis of arbutin in engineered Escherichia coli. Metab Eng 42: 52-58. doi:10.1016/j .ymben.2017.06.001

Shibuya M, Nishimura K, Yasuyama N, Ebizuka Y. 2010. Identification and characterization of glycosyltransferases involved in the biosynthesis of soyasaponin I in Glycine max. FEBS Lett 584: 2258-2264. doi:10.1016/j.febslet .2010 .03 .037

Sønderby IE, Geu-Flores F, Halkier BA. 2010. Biosynthesis of glucosinolates-Gene discovery and beyond. Trends Plant Sci 15: 283-290. doi:10.1016/j.tplants.2010.02.005

Song C, Härtl K, McGraphery K, Hoffmann T, Schwab W. 2018. Attractive but toxic: Emerging roles of glycosidically bound volatiles and glycosyltransferases involved in their formation. Mol Plant 11: 1225-1236. doi:10.1016/j .molp.2018.09.001

Stephenson MJ, Reed J, Brouwer B, Osbourn A. 2018. Transient expression in Nicotiana benthamiana leaves for triterpene production at a preparative scale. J Vis Exp 138: 58169. doi:10.3791/58169

Takagi K, Yano R, Tochigi S, Fujisawa Y, Tsuchinaga H, Takahashi Y, Takada Y, Kaga A, Anai T, Tsukamoto C, et al. 2018. Genetic and functional characterization of Sg4 glycosyltransferase involved in the formation of sugar chain structure at the C-3 position of soybean saponins. Phytochemistry 156: 96-105. doi:10.1016/j.phytochem .2018 .09 .002

Takos AM, Knudsen C, Lai D, Kannangara R, Mikkelsen L, Motawia MS, Olsen CE, Sato S, Tabata S, Jørgensen K, et al. 2011. Genomic clustering of cyanogenic glucoside biosynthetic genes aids their identification in Lotus japonicus and suggests the repeated evolution of this chemical defence pathway. Plant J 68: 273-286.
Tamura K, Stecher G, Peterson D, Filipski A, Kumar S. 2013. MEGA6: Molecular evolutionary genetics analysis version 6.0. Mol Biol Evol 30: 2725-2729. doi:10.1093/mol $\mathrm{bev} / \mathrm{mst} 197$

Tárraga S, Lisón P, López-Gresa MP, Torres C, Rodrigo I, Bellés JM, Conejero V. 2010. Molecular cloning and characterization of a novel tomato xylosyltransferase specific for gentisic acid. J Exp Bot 61: 4325-4338. doi:10.1093/ jxb/erq234

Theis N, Raguso RA. 2005. The effect of pollination on floral fragrance in thistles. J Chem Ecol 31: 2581-2600. doi:10 .1007/s10886-005-7615-9

Tohge T, Nishiyama Y, Hirai MY, Yano M, Nakajima J, Awazuhara M, Inoue E, Takahashi H, Goodenowe DB, Kitayama M, et al. 2005. Functional genomics by integrated analysis of metabolome and transcriptome of Arabidopsis plants over-expressing an MYB transcription factor. Plant J 42: 218-235. doi:10.1111/j.1365-313X.2005 .02371.x

Töpfer N, Fuchs LM, Aharoni A. 2017. The PhytoClust tool for metabolic gene clusters discovery in plant genomes. Nucleic Acids Res 45: 7049-7063. doi:10.1093/nar/gkx404

Trossat C, Rathinasabapathi B, Weretilnyk EA, Shen TL, Huang ZH, Gage DA, Hanson AD. 1998. Salinity promotes accumulation of 3-dimethylsulfoniopropionate and its precursor $S$-methylmethionine in chloroplasts. Plant Physiol 116: 165-171. doi:10.1104/pp.116.1.165

Vetter J. 2000. Plant cyanogenic glycosides. Toxicon 38: 11-36. doi:10.1016/S0041-0101(99)00128-2

Vincken JP, Heng L, de Groot A, Gruppen H. 2007. Saponins, classification and occurrence in the plant kingdom. Phytochemistry 68: 275-297. doi:10.1016/j.phytochem .2006 .10 .008

Vogt T, Jones P. 2000. Glycosyltransferases in plant natural product synthesis: characterization of a supergene family. Trends Plant Sci 5: 380-386. doi:10.1016/S1360-1385(00) 01720-9

Wang X. 2009. Structure, mechanism and engineering of plant natural product glycosyltransferases. FEBS Lett 583: 3303-3309. doi:10.1016/j.febslet.2009.09.042

Wang J, Ma XM, Kojima M, Sakakibara H, Hou BK. 2011. $\mathrm{N}$-glucosyltransferase UGT76C2 is involved in cytokinin homeostasis and cytokinin response in Arabidopsis thaliana. Plant Cell Physiol 52: 2200-2213. doi:10.1093/pcp/ pcr152

Wang J, Ma XM, Kojima M, Sakakibara H, Hou BK. 2013. Glucosyltransferase UGT76C1 finely modulates cytokinin responses via cytokinin $N$-glucosylation in Arabidopsis thaliana. Plant Physiol Biochem 65: 9-16. doi:10.1016/ j.plaphy.2013.01.012

Wang P, Wei Y, Fan Y, Liu Q, Wei W, Yang C, Zhang L, Zhao G, Yue J, Yan X, et al. 2015. Production of bioactive ginsenosides $\mathrm{Rh} 2$ and $\mathrm{Rg} 3$ by metabolically engineered yeasts. Metab Eng 29: 97-105. doi:10.1016/j.ymben .2015 .03 .003

Wang H, Wang C, Fan W, Yang J, Appelhagen I, Wu Y, Zhang P. 2018. A novel glycosyltransferase catalyses the transfer of glucose to glucosylated anthocyanins in purple sweet potato. J Exp Bot 69: 5444-5459. doi:10.1093/jxb/ ery305

Wei W, Wang P, Wei Y, Liu Q, Yang C, Zhao G, Yue J, Yan X, Zhou Z. 2015. Characterization of Panax ginseng 
Plant Natural Product Glycosylation

UDP-glycosyltransferases catalyzing protopanaxatriol and biosyntheses of bioactive ginsenosides $\mathrm{F} 1$ and $\mathrm{Rh} 1$ in metabolically engineered yeasts. Mol Plant 8: $1412-$ 1424. doi:10.1016/j.molp.2015.05.010

Weston LA, Mathesius U. 2013. Flavonoids: Their structure, biosynthesis and role in the rhizosphere, including allelopathy. J Chem Ecol 39: 283-297. doi:10.1007/s10886013-0248-5

Wetterhorn KM, Newmister SA, Caniza RK, Busman M, McCormick SP, Berthiller F, Adam G, Rayment I. 2016. Crystal structure of Os79 (Os04g0206600) from Oryza sativa: A UDP-glucosyltransferase involved in the detoxification of deoxynivalenol. Biochemistry 55: 6175-6186. doi:10.1021/acs.biochem.6b00709

Wetterhorn KM, Gabardi K, Michlmayr H, Malachova A, Busman M, McCormick SP, Berthiller F, Adam G, Rayment I. 2017. Determinants and expansion of specificity in a trichothecene UDP-glucosyltransferase from Oryza sativa. Biochemistry 56: 6585-6596. doi:10.1021/acs .biochem.7b01007

Wilson AE, Feng X, Ono NN, Holland D, Amir R, Tian L. 2017. Characterization of a UGT84 family glycosyltransferase provides new insights into substrate binding and reactivity of galloylglucose ester-forming UGTs. Biochemistry 56: 6389-6400. doi:10.1021/acs.biochem.7b00946

Xiao M, Zhang Y, Chen X, Lee EJ, Barber CJ, Chakrabarty R, Desgagne-Penix I, Haslam TM, Kim YB, Liu E, et al. 2013. Transcriptome analysis based on next-generation sequencing of non-model plants producing specialized metabolites of biotechnological interest. J Biotechnol 166: 122-134. doi:10.1016/j.jbiotec.2013.04.004

Xu GJ, Cai W, Gao W, Liu CS. 2016. A novel glucuronosyltransferase has an unprecedented ability to catalyse continuous two-step glucuronosylation of glycyrrhetinic acid to yield glycyrrhizin. New Phytol 212: 123-135. doi:10 $.1111 / \mathrm{nph} .14039$

Xue F, Guo H, Hu Y, Liu R, Huang L, Lv H, Liu C, Yang M, Ma L. 2016. Expression of codon-optimized plant glycosyltransferase UGT72B14 in Escherichia coli enhances salidroside production. Biomed Res Int 2016: 9845927. doi:10.1155/2016/9845927
Yang M, Fehl C, Lees KV, Lim EK, Offen WA, Davies GJ, Bowles DJ, Davidson MG, Roberts SJ, Davis BG. 2018. Functional and informatics analysis enables glycosyltransferase activity prediction. Nat Chem Biol 14: 11091117. doi:10.1038/s41589-018-0154-9

Yonekura-Sakakibara K, Hanada K. 2011. An evolutionary view of functional diversity in family 1 glycosyltransferases. Plant J 66: 182-193. doi:10.1111/j.1365-313X.2011 .04493.x

Yonekura-Sakakibara K, Tohge T, Niida R, Saito K. 2007. Identification of a flavonol 7-O-rhamnosyltransferase gene determining flavonoid pattern in Arabidopsis by transcriptome coexpression analysis and reverse genetics. J Biol Chem 282: 14932-14941. doi:10.1074/jbc.M6 11498200

Yonekura-Sakakibara K, Tohge T, Matsuda F, Nakabayashi R, Takayama H, Niida R, Watanabe-Takahashi A, Inoue E, Saito K. 2008. Comprehensive flavonol profiling and transcriptome coexpression analysis leading to decoding gene-metabolite correlations in Arabidopsis. Plant Cell 20: 2160-2176. doi:10.1105/tpc.108.058040

Yoon JA, Kim BG, Lee WJ, Lim Y, Chong Y, Ahn JH. 2012. Production of a novel quercetin glycoside through metabolic engineering of Escherichia coli. Appl Environ Microbiol 78: 4256-4262. doi:10.1128/AEM.00275-12

Yu F, Utsumi R. 2009. Diversity, regulation, and genetic manipulation of plant mono- and sesquiterpenoid biosynthesis. Cell Mol Life Sci 66: 3043-3052. doi:10.1007/ s00018-009-0066-7

Zhuang Y, Yang GY, Chen X, Liu Q, Zhang X, Deng Z, Feng Y. 2017. Biosynthesis of plant-derived ginsenoside Rh2 in yeast via repurposing a key promiscuous microbial enzyme. Metab Eng 42: 25-32. doi:10.1016/j.ymben.2017 .04 .009

Zong G, Li J, Gao Y, Fei S, Liu X, Wang X, Shen Y. 2019. Overexpression, purification, biochemical and structural characterization of rhamnosyltransferase UGT89C1 from Arabidopsis thaliana. Protein Expr Purif 156: 44-49. doi:10.1016/j.pep.2018.12.007 


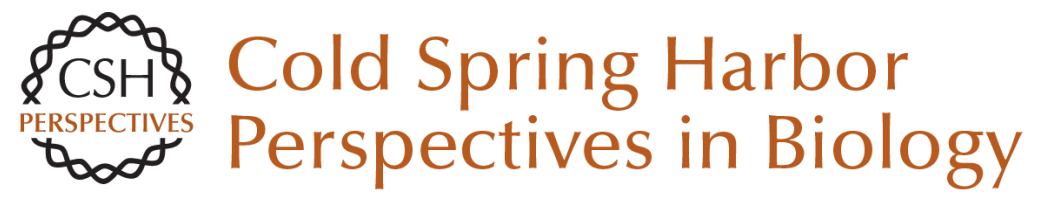

\section{The Sweet Side of Plant-Specialized Metabolism}

Thomas Louveau and Anne Osbourn

Cold Spring Harb Perspect Biol 2019; doi: 10.1101/cshperspect.a034744 originally published online June 24, 2019

\section{Subject Collection Engineering Plants for Agriculture}

Plant Inflorescence Architecture: The Formation, Activity, and Fate of Axillary Meristems Yang Zhu and Doris Wagner

Sub1 Rice: Engineering Rice for Climate Change Kyle Emerick and Pamela C. Ronald

Engineering Disease-Resistant Cassava Z.J. Daniel Lin, Nigel J. Taylor and Rebecca Bart

Many Facets of Dynamic Plasticity in Plants Xiaodong Yang and Sally A. Mackenzie

How Do Strigolactones Ameliorate Nutrient Deficiencies in Plants?

Kaori Yoneyama

Mechanisms and Impact of Symbiotic Phosphate Acquisition Chai Hao Chiu and Uta Paszkowski
The Sweet Side of Plant-Specialized Metabolism Thomas Louveau and Anne Osbourn

The Role of Dwarfing Traits in Historical and Modern Agriculture with a Focus on Rice Ángel Ferrero-Serrano, Christian Cantos and Sarah M. Assmann

Bt Brinjal in Bangladesh: The First Genetically Engineered Food Crop in a Developing Country Anthony M. Shelton, Md. J. Hossain, Vijay Paranjape, et al.

Circadian Rhythms in Plants Nicky Creux and Stacey Harmer

Developing Blight-Tolerant American Chestnut Trees William A. Powell, Andrew E. Newhouse and Vernon Coffey

Stomatal Development and Perspectives toward Agricultural Improvement Hitoshi Endo and Keiko U. Torii

For additional articles in this collection, see http://cshperspectives.cshlp.org/cgi/collection/

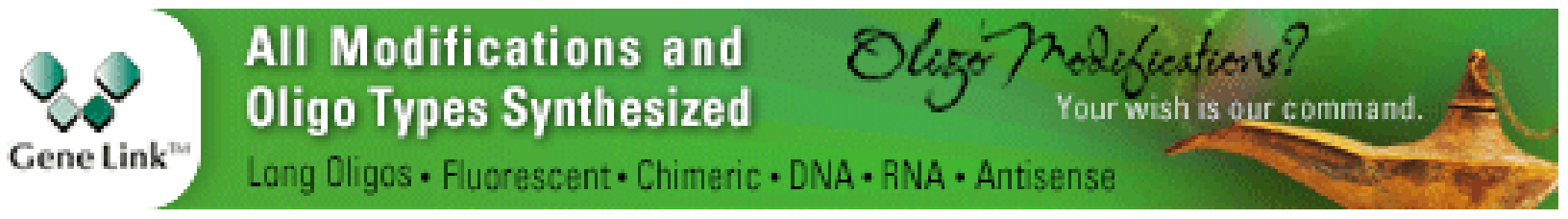

